\title{
Eliminating supportive crowds reduces referee bias
}

\author{
by J. James Reade, Dominik Schreyer \\ and Carl Singleton
}

Discussion Paper No. 2020-25

Department of Economics

University of Reading

Whiteknights

Reading

RG6 6AA

United Kingdom

www.reading.ac.uk 


\title{
Eliminating supportive crowds reduces referee bias
}

\author{
J. James Reade \\ Dominik Schreyer \\ Carl Singleton* \\ University of Reading \\ WHU - Otto Beisheim School of Management \\ University of Reading
}

Accepted at: Economic Inquiry (2021; In Press)

\begin{abstract}
We use a series of historical natural experiments in association football to test whether social pressure from a home stadium crowd affected behaviour and outcomes. The standout effect of an empty stadium was that referees cautioned visiting players less often, by over a third of a yellow card per match or once for every twenty-two fouls committed. Stadium crowds caused referees to favour the home team in their decision making. Empty stadiums appear to have reduced the overall home advantage in the final outcomes of football matches, but we cannot statistically reject no effect.
\end{abstract}

Keywords: Home Advantage, Referee Bias, Social Pressure, Attendance, Natural Experiments, Coronavirus

JEL codes: C90, D91, L83

j.j.reade@ @reading.ac.uk (+44 118378 5062), Professor of Economics, \& c.a.singleton@ reading.ac.uk (corresponding author; +44 118378 7864), Associate Professor in Economics, Department of Economics, University of Reading, Whiteknights Campus, RG6 6EL, UK. dominik.schreyer@whu.edu (+49 211 44709 743), Director of Center for Sports and Management (CSM), WHU - Otto Beisheim School of Management, Erkrather Str. 224a, 40233 Düsseldorf, Germany. We would like to thank Antonio Cabrales, Marina Della Giusta, Justus Haucap, Dane McCarrick, Rachel Scarfe, Daniel Schaefer, and Paul Telemo for helpful comments, as well as participants in the Reading Online Sport Seminars in March 2020 and the 96th Annual Conference of the Western Economic Association on 2021. This research did not receive any specific grant from funding agencies in the public, commercial, or not-for-profit sectors. An earlier working paper was published as "Echoes: what happens when football is played behind closed doors?" (Reade et al., 2020a). Following further comments and advice, we have updated this to reflect the progression in the literature since Covid-19 and to improve our empirical strategy. 


\section{INTRODUCTION}

Social forces and pressure have the potential to affect behaviour, decision making and economic outcomes (e.g., Akerlof, 1980; Bernheim, 1994; Becker and Murphy, 2000). In this regard, there is growing experimental evidence that individuals make different and potentially biased decisions in situations where there is some form of salient group membership (e.g., Charness et al., 2007; Charness and Sutter, 2012). There is also evidence from real-life settings that a crowd can bias the decision making of an individual toward its preferred outcome. Specifically, home team support in a professional sports contest can impact on the officials' decisions (see the summary by Dohmen and Sauermann, 2016). ${ }^{1}$ In fact, fans in a football crowd believe that they do affect the outcome of a match in their own team's favour, by influencing the referee's decisions (Wolfson et al., 2005).

In this paper, we exploit a series of natural experiments in high stakes European professional football when matches had to take place in empty stadiums, to ask whether playing 'behind closed doors' disproportionately affected outcomes. These experiments typically occurred when football teams were banned form admitting supporters into their stadiums as one-off punishments for bad behaviour off the football pitch (e.g., due to corruption, racist abuse or violence). These events provide clean breaks in the presence or absence of a large crowd of emotional spectators, which could affect the decisions and behaviour of the participants in a contest. We can also address the question of why individuals and teams perform better in more familiar locations, normally referred as home advantage in professional sports (e.g., Schwartz and Barsky, 1977). Besides the impact of a crowd, familiarity and fatigue from travel have been put forward as explanations for why a team or individual playing at home tends to have an increased chance of winning a contest. Since closed doors football matches took place in the same venue and at the same time as they would have done if supporters were not banned, we can focus on the impact of the crowd.

We study 160 matches that took place behind closed doors since the beginning of the 2002/03 European season and before April 2020, comparing them with over thirty-three thousand other matches across the same competitions and period. On average, the home team won $36 \%$ of the time in empty stadiums, compared with $46 \%$ when fans were present. This was mirrored by a significant

\footnotetext{
${ }^{1}$ This is just one area where the competitive and well-defined environments within sports have provided laboratories to study human behaviour, to test theories, and to observe the effects of policy. See Bar-Eli et al. (2020) for a recent essay on the clarity that sporting contexts can provide for social scientists.
} 
increase in the percentage of matches won by the away team in closed doors matches, accounted for by fewer goals being scored by the home teams. These patterns were common across the different represented competitions: in Italian, French and cross-border European football. However, when we account for the selection of different team qualities into these rare closed doors matches and look for a causal interpretation, the effect of playing without fans on home advantage is reduced and not statistically significant.

We also study whether playing football behind closed doors was associated with differences in what happened within matches. Although there was no difference in the frequency or severity of how the referee disciplined the home team, there were significant differences for the away team. With fans in the stadium, away teams were awarded on average a third of a yellow card more per match than home teams. This difference was generally cancelled out when teams played behind closed doors, with $20 \%$ fewer cards awarded to the away teams compared with having fans in attendance. At the same time, the empty stadiums did not affect the amount of foul play. These results suggest that the complete absence of a crowd in a football match eliminates the bias against the away team in punishments, normally caused by social pressure from the mostly home-team-supporting fans. This is broadly consistent with a study by Pettersson-Lidbom and Priks (2010) (henceforth PLP) of 21 Italian closed doors matches in 2006/07, which also feature in our sample. We extend this previous study by increasing the sample size considerably, addressing the selection of participant characteristics into the matches played without fans, and looking at other outcomes besides punishments for foul play.

Our results are particularly relevant at the present time, as global professional sport largely had to take place behind closed doors in the months following the start of the Covid-19 pandemic in early 2020. For example, the Tokyo Summer Olympic Games took place without crowds in July and August of 2021, and unrestricted crowds only returned to English Premier League football stadiums in August 2021. Several studies, summarised in what follows and including one by ourselves (Bryson et al., 2021), have studied the effects of playing football in empty stadiums following the Spring 2020 shutdown of the professional game. However, it is not as clear in the post-Covid-19 data that the empty stadiums was the only thing that changed. Temporary new rules on the number and timing of substitutions in matches were introduced, which could have affected tactics and play. Further, it is plausible that the presence of the virus altered the competitiveness 
of matches, with players avoiding close contact and referees becoming more protective, resulting in either more or less fouls and punishments. Therefore, our analysis here provides a baseline and arguably less contaminated view on how much social pressure from a football crowd affects behaviour and decision making. It also serves to bridge the gap between the 21 closed doors football matches studied by PLP, before Covid-19, and the thousands studied after Covid-19, by numerous authors and using a large variety of methods and sub-samples.

This paper continues as follows: in Section II, we discuss some background and related literature, with a focus on the post-Covid-19 period; in Section III, we describe our analysis dataset of football matches; in Section IV, we present our empirical strategy and the main results; and in Section V, we offer some concluding remarks.

\section{BACKGROUND \& RELATED LITERATURE}

\section{II.i Home advantage and referee bias in professional sports}

There is a long tradition in the social sciences of analysing and explaining the causes of home advantage in professional sports (e.g., Courneya and Carron, 1992; Nevill and Holder, 1999; Pollard and Pollard, 2005; Schwartz and Barsky, 1977). Across the different sporting environments, most authors attribute a significant home advantage to three intervening factors (c.f., Balmer et al., 2003): (1) a visiting team's fatigue due to travel, (2) a lack of familiarity with the venue and its environment, and (3) the social support from home spectators, which might induce bias from referees and other officials (e.g., Sutter and Kocher, 2004). In an early and influential study, Schwartz and Barsky (1977) pointed toward greater home advantage within indoor sports, such as basketball and ice

hockey, than outdoor, such as American football, finding that the home crowd's support appeared to be a significant factor. Subsequently, a large body of literature has loosely replicated this original finding across different sporting environments, documenting notable positive home crowd effects in sports as diverse as football (e.g., Ponzo and Scoppa, 2018), basketball (e.g., Boudreaux et al., 2017), and skeleton (e.g., Chun and Park, 2021). However, complementary evidence also exists that such supportive crowds can induce unwanted effects on some athletes, who may then choke under 
(too much) pressure (e.g., Böheim et al., 2019; Dohmen, 2008a; Harb-Wu and Krumer, 2019; Jane, 2021).

In association football, the home crowd's potential to induce referee bias towards the home team has attracted considerable research interest. ${ }^{2}$ In an early example of this interest and a rare experimental setting involving qualified English referees, Nevill et al. (2002) found that background noise significantly affected judgements of what constituted foul play, with decisions becoming less certain and increased bias toward the home team. Garicano et al. (2005) and Sutter and Kocher (2004) also identified a systematic bias among referees in the top levels of Spanish and German football, respectively. In particular, they found that referees behaved as if to satisfy the home crowd, by systematically shortening matches when the home team was winning and lengthening them when the home team was losing. Garicano et al. (2005) also used variation in crowd size and composition to suggest that social pressure was the cause of this referee bias. Similar effects of the crowd on referees' injury time decisions were documented by Dohmen (2008b) for German football and Scoppa (2008) for Italian football. Further, Rocha et al. (2013) showed that this source of referee bias was more prevalent in Brazilian football when matches were televised. Looking at other football referee decisions and studying punishments for foul play, Dawson et al. (2007) found that home teams tended to accumulate fewer red and yellows cards than away teams, with this not relating to home advantage, but instead appearing to be driven by referee bias. Extending this analysis to international football, Dawson and Dobson (2010) identified the nationality of referees as another factor affecting their favouritism toward one team or another. Buraimo et al. (2010) and Buraimo et al. (2012) found further convincing evidence that social pressure affects the punishment decisions of referees, by accounting for the specific patterns of play within English, German and Spanish top league matches. They also found that the presence of a running track in the stadium, increasing the distance between the fans and the referee, tended to reduce the bias against the away team. However, Goumas (2014) found that a crowd's density was the most important factor in European football, rather than its size or proximity to the pitch. While this evidence suggests a somewhat gloomy view on the impartiality of referees in professional football, or at least on their ability to resist the social pressure from the stadium crowd, Page and Page (2010) showed that some referees

\footnotetext{
${ }^{2}$ There is also a closely related literature that describes how the scheduling of football matches and the ability of (away) supporters to attend can affect outcomes on the pitch, potentially through effects on referee decision making (e.g., Belchior, 2020; Colella et al., 2018; Goller and Krumer, 2020; Ponzo and Scoppa, 2018).
} 
are more susceptible to being influenced by the crowd than others. ${ }^{3}$ Extrapolating from the sum of all this evidence suggests that playing professional football without a stadium crowd should lead to a substantially reduced advantage for the team playing at home.

\section{II.ii Covid-19, closed doors, home advantage and referee bias}

The return of most major European football leagues in the Summer of 2020, amid the waning first wave of Covid-19, created a rare opportunity to study the regular absence of social pressure from a stadium crowd. Following a two-month hiatus, on 16 May, 2020, German professional football was the first to return without fans attending. Followers of German football took to calling this new format of the Bundesliga "Geisterspiele" or "ghost games". Shortly after, most of European football's top-flights returned in empty stadiums, while the French Ligue 1 was the highest profile league that failed to resume the 2019-20 season. A minority of European leagues, such as the Danish Superliga, the Swiss Super League, and the Russian Premier League, eventually returned to complete the 2019/20 season with some restricted numbers of fans in attendance (e.g., Cueva, 2020). Only a few football leagues worldwide, most prominently the Belarussian Premier League (Reade et al., 2020b), kept playing with unrestricted crowds throughout this first wave.

To the best of our knowledge, these events have so far motivated 39 empirical studies on the (causal) effects of an absent crowd on both player performances and referee decision making, 23 of which had undergone peer-review and been published as of 30 September, 2021 (i.e., either online first or in print). Below, we summarise the key findings of these published studies, distinguishing between those focusing on association football (21) and other sports (2). However, first we provide a descriptive account of what happened to home advantage in European professional football either side of the the Covid-19 shutdown.

\section{II.ii.1 Describing home advantage in football before and after Covid-19}

To provide an overview of what appears to have happened to home advantage in elite European football after Covid-19, we collected data on outcomes from all of the 51,333 matches that took

\footnotetext{
${ }^{3}$ There is some comparable literature from other sports. In a convincing example away from football, Sacheti et al. (2015) identified the home bias of international cricket umpires, exploiting rule changes governing whether they could share the same nationality as the teams playing. They found that these natural experiments decreased the bias toward the home team but there was no evidence that the mechanism behind this was social pressure from the home crowd acting on home-based umpires.
} 
place in the 2011/12-2020/21 seasons in the top leagues of each country in the top 30 of the official UEFA Association club coefficients (as of 1 October 2021, worldfootball.net). The solid lines in the four panels of Figure 1 plot the monthly sample means of four different match outcomes across these 30 leagues. The top-left and top-right panels plot the monthly percentages of league matches ending in a win for the team playing at home and the team playing away from home, respectively, with statistics for the residual draw outcome not shown. Together with the bottom-left panel of Figure 1, which shows the monthly average goal difference (home minus away), these plots give a sense of whether there were trends in the extent of home advantage before the March 2020 Covid-19 shutdown of all the leagues.

There appears to have been a trend of reducing home advantage, since the beginning of the 2017/18 season, with more away wins and lower goal differences. After the leagues restarted in May 2021, it appears as though home advantage expressed in match wins and goals scored further decreased, though not necessarily deviating from the pre-Covid-19 trend over the few seasons of matches before the pandemic arrived. The bottom-right panel of Figure 1, however, shows a clearer difference before and after Covid-19, with the advantage for home teams of being being awarded fewer yellow cards (punishments by referees) somewhat eroded after the April 2020 shutdown.

In Figure 1, we also show monthly sample means of outcomes after April 2020 according to whether matches took place without a stadium crowd (triangle markers) or a crowd significantly restricted in size (circle markers). ${ }^{4}$ There is a pattern of greater home advantage in terms of goals and wins in the sample with restricted crowds compared to before Covid-19, but no clear change in terms of yellow cards. Vice versa, without a stadium crowd, especially in the early months following the May 2020 restart, Figure 1 generally shows reduced home advantage compared with before the shutdown in terms of wins, goals and yellow cards. However, playing elite football after Covid-19 behind closed doors, with restricted crowds, or with unrestricted crowds, was not randomly distributed over time, leagues or teams, which could make the before and after Covid-19 comparisons using Figure 1 somewhat spurious. The literature summarised in the next section has attempted to draw more robust inferences about the effects on outcomes in football and other professional sports

\footnotetext{
${ }^{4}$ Of all 9,363 matches in the sample between April 2020 and the start of October 2021, 4,153 were played without a stadium crowd and 969 were played with a restricted crowd, where we defined the latter as a reported stadium attendance greater than zero but less than $50 \%$ of the average for the same home team in the 2018/19 season.
} 
FIGURE 1: Average monthly outcomes in European Football's top leagues, seasons $2011 / 12-2020 / 21$
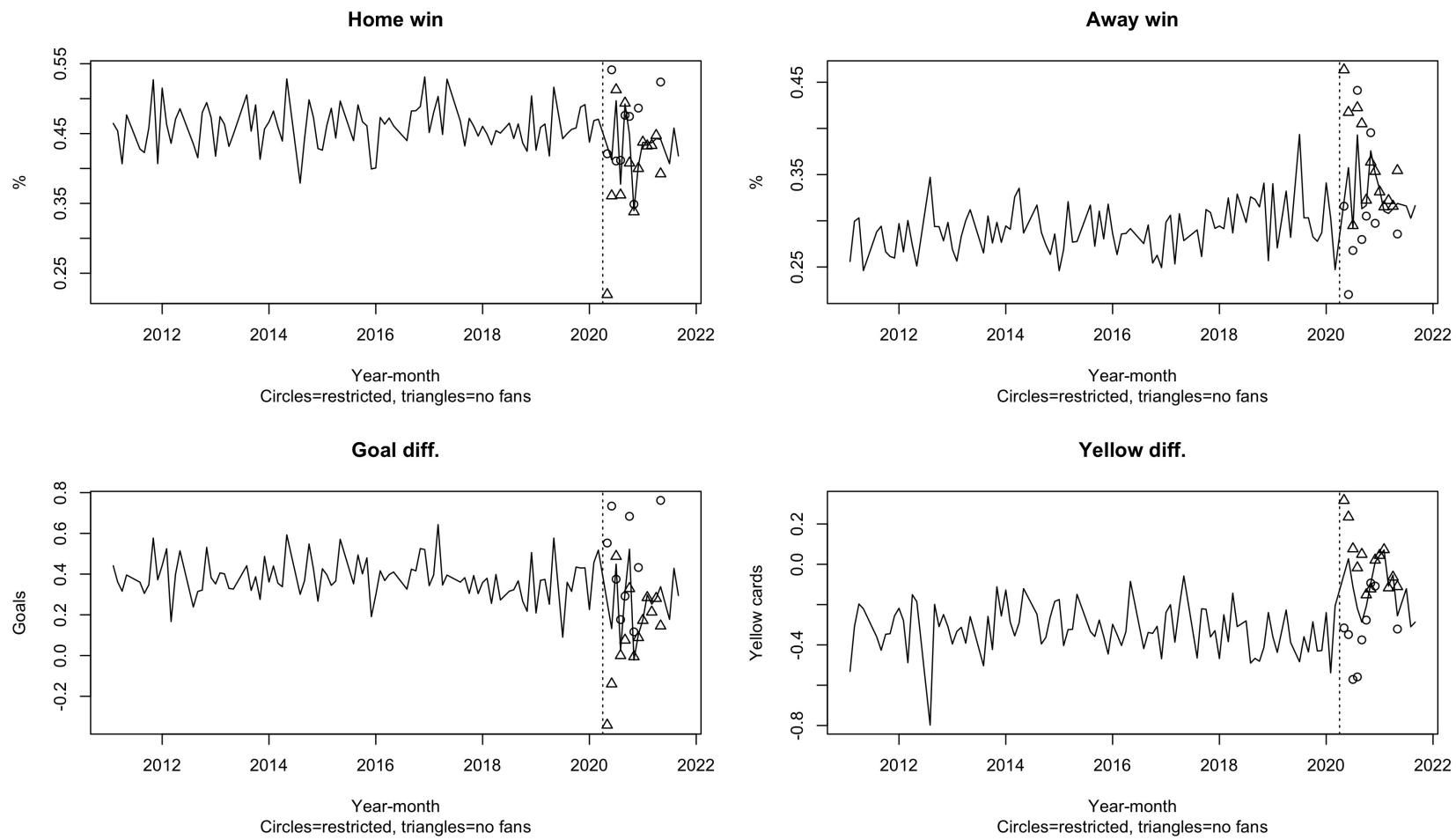

Notes.- Uses all matches in the top professional league of each country ranked in the top 30 of UEFA Association club coefficients as of 1 October 2021; https://www.uefa.com/memberassociations/uefarankings/. The solid line gives the sample mean for all matches played in a month. Circles are sample means within a month of matches where less than $50 \%$ of fans attended compared with for the same home team in the 2018/19 season. Triangles are sample means within a month of matches that took place behind closed doors, with no fans officially allowed to attend. The vertical dashed line indicates the Covid-19 induced shutdown of European Football from April 2021. Source.- author calculations using worldfootball.net; accessed 1 October 2021.

of playing either without or with substantially reduced social pressure from a stadium crowd in the aftermath of Covid-19.

\section{II.ii.2 The still-emerging literature on how Covid-19 affected home advantage in football}

Table 1 gives an overview of 21 peer-reviewed manuscripts analysing the (causal) effects of an absent crowd on association football during Covid-19. As the table shows, these studies vary significantly in terms of their scope. While a few have analysed matches played in only one particular league (e.g., Subak and Kaya, 2021) or a specific country (e.g., Endrich and Gesche, 2020), others have generated more extensive samples, peaking at 23 different leagues from multiple levels of the football pyramid within the 2019/20 season in Bryson et al. (2021). Some of these studies have also significantly extended the period of comparison to well before Covid-19 (e.g., Scoppa, 2021). Most of the studies 
have focused on final match outcomes and the within match decisions by referees to punish teams, differing substantially in methods, from empirical designs aimed at convincing the reader about causal inference to reporting some descriptive statistics. Ferraresi and Gucciardi (2021) is a notable exception in this literature, in so far as this study focuses on the impact of an absent crowd on player performances during penalty kicks, thus studying what happens after a referee's input of awarding a penalty.

While most of the studies in Table 1 document a significant decrease in home advantage when association football teams play regularly behind closed doors, there is as yet no consensus on the underlying causal mechanisms, primarily because the reported effects capturing a potential home advantage are many and varied. For instance, some authors have demonstrated a largely robust and arguably causal reduction in the number of yellow cards awarded to the away team (e.g., Bryson et al., 2021; Endrich and Gesche, 2020; Scoppa, 2021). Similarly, some have observed that the foul ratio changed to the disadvantage of the home team without crowds present (e.g., Endrich and Gesche, 2020), while other aspects of the match, such as the total number of goals scored, remained largely unaffected (e.g., Sánchez and Lavín, 2021; Scoppa, 2021). However, turning to match outcomes, there are some contradictory findings. For instance, Bryson et al. (2021) found no significant effect of the empty stadiums on the likelihood of a home win when pooling estimates over several leagues and countries within the 2019/20 season, a finding that is largely in contrast to the results presented by Scoppa (2021) and some others, whose empirical approaches tend to compare what happened after Covid-19 with football matches before the 2019/20 season. As Benz and Lopez (2021) found, in some leagues home advantage might have even increased.

Although all but one of the twenty-three studies summarised in Table 1 have shown some effects of playing behind closed doors on home advantage, there are nonetheless differences in their conclusions. Based on our reading of the extant literature, there are three potential explanations for these differences. First, only some studies chose to identify the within-season effects of playing without crowds, thus avoiding potentially confounding contextual effects, such as the long-term trend of decreasing home advantage in some European football competitions (e.g., Peeters and van Ours, 2021) or the introduction of the Video Assistant Referee (VAR). Second, aggregating and pooling over large quantities of historical data could have generated more precise estimates of the closed doors football effect, and this has generally led to different inferences rather than different 
estimated effect sizes. Third, there is significant variation in the number of leagues and countries studied, raising the question of whether some of the results are prone to sample selection bias or type 1 errors in small samples. In fact, as Benz and Lopez (2021) discussed, most of the earlier studies chose to pool estimation samples across football leagues rather than treat each in isolation. When Benz and Lopez (2021) studied league-specific results, they noted that home advantage declined significantly within the 2019/20 season after a post-Covid-19 resumption in some but not all 17 of the European leagues in their sample. Somewhat similarly, Fischer and Haucap (2021) observed heterogeneity in the effects of hosting ghost games across the three top-flights of the German football pyramid, showing that the impacts of playing behind closed doors was less dramatic for those teams in Bundesliga 2 and 3. Liga, i.e., those teams used to playing in stadiums with relatively low occupancy rates. This observation is consistent with findings from Ferraresi and Gucciardi (2021), among others, who observed that the decline in home advantage from an absent crowd during penalty kicks is more pronounced for home teams who are used to high stadium attendances.

\section{II.ii.3 Covid-19 and home advantage in other sports}

While there is already plenty of empirical research on the effects of playing association football without a stadium crowd, a comparable literature focusing on other sports is only just emerging. To the best of our knowledge, there are two such peer-reviewed studies so far, and these come to different conclusions, somewhat resembling our observations on football, albeit for different North American sports and relatively small post-Covid-19 samples of games without stadium crowds. In Major League Baseball, Losak and Sabel (2021) noted no significant difference in home-field advantage between 2019 (with spectators) and 2020 (without). However, Guérette et al. (2021) observed that the typical home advantage declined when ice hockey was played behind closed doors in both the Canadian Hockey League and the National Hockey League. The tendency for inconsistency across studies is likely to continue beyond football. Authors with working papers looking at North American sports also come to different conclusions, depending on the sporting environment, the sampling and the methods used (e.g., Szabó, 2021). 


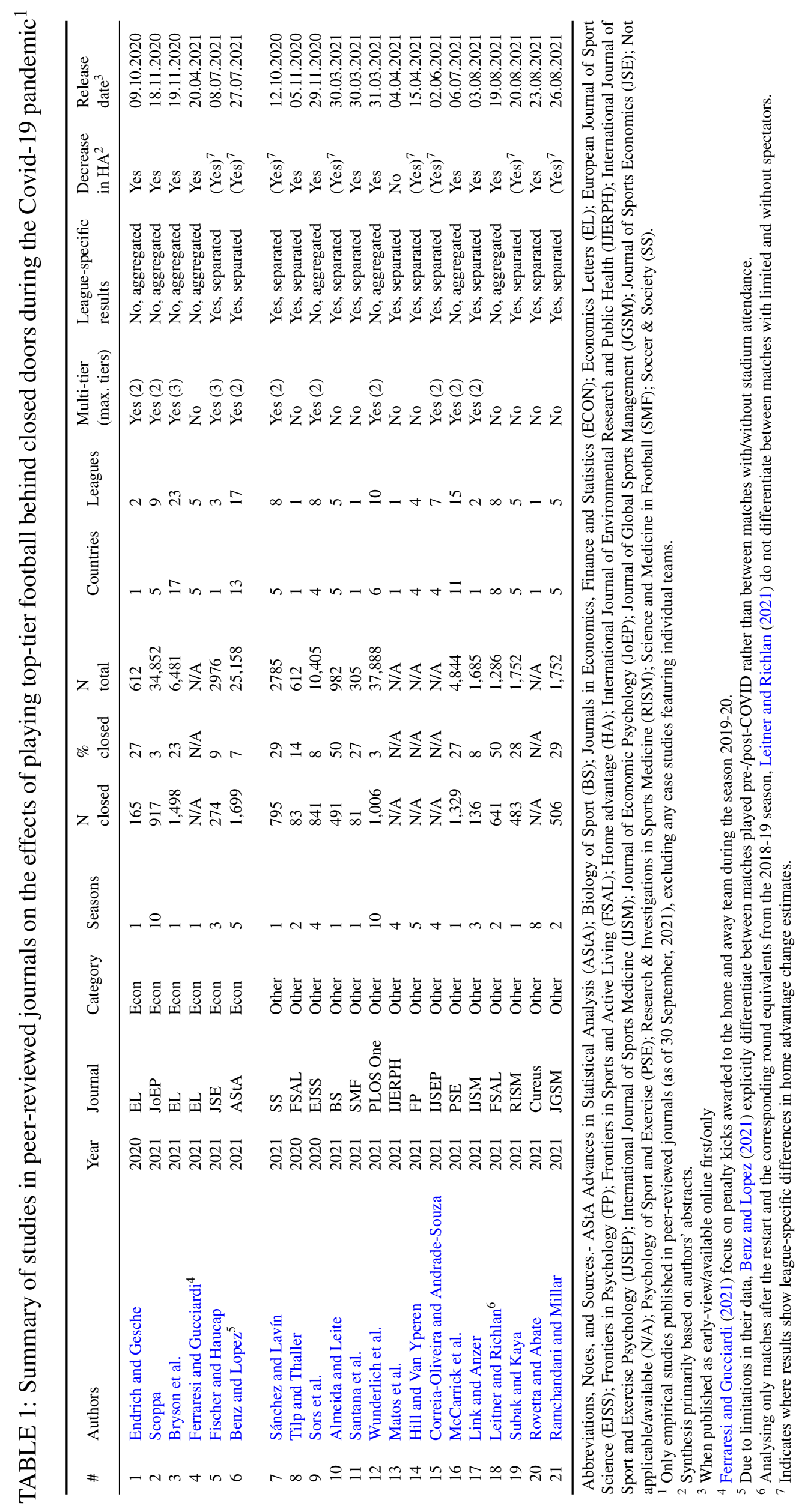




\section{II.iii Summary}

Before Covid-19, many researchers had used natural variation over match venues, in terms of stadium capacities, features and attendances, to test whether referee bias toward the home team in professional football could be explained by social pressure from the stadium crowd. Some studies had also used variation in the state of play when referees made their decisions, in particular whether the match scoreline was close and in favour of the home team when the amount of additional time for earlier stoppages was decided at the end of a match. When Covid-19 led to football stadiums around the world being mostly emptied, researchers (including ourselves in Bryson et al., 2021) viewed this as a natural experiment to study the impacts of a stadium crowd.

This new wave of research has been almost comprehensive in concluding that home advantage in final match outcomes was significantly reduced without crowds after Covid-19, throughout professional football and in many countries. Some of these studies have also pointed toward the effect of social pressure from the crowd on referee bias as the main mechanism, because punishments against the away team for foul play were significantly reduced without crowds. This literature, however, shows substantial heterogeneity in the apparent effects of playing football without a stadium crowd, across competitions and within the 2019/20 season, as demonstrated by Bryson et al. (2021) and Benz and Lopez (2021). Within the literature published so far, these two studies have arguably been the most conservative about how to reach a causal interpretation on home advantage and referee bias from comparing before and after Covid-19. This is because of the long-term trend of declining home advantage in professional football, as well as other Covid-19 related factors that potentially affected professional sport outcomes and home advantage, such as fixture fatigue interacting with travel fatigue, as authorities attempted to complete seasons in periods that were shorter than normal, and in some cases there being new rules (e.g., more player substitutions allowed). Nevertheless, from studying just 21 matches played without spectators in Italy during the 2006/07 season, PLP found similar patterns to the studies that came after the pandemic. To bridge this gap, between the results using 21 matches in Italy and others using thousands of matches that took place globally without crowds because of Covid-19, in the remainder of the paper we substantially extend PLP's pre-Covid-19 sample and analysis of empty football stadiums. 


\section{DATA}

We explore all football matches since the beginning of the 2002/03 European season in the following seven competitions: (1) UEFA Champions League, (2) UEFA Europa League, (3) French Ligue 1, (4) Italian Serie A, (5) Italian Serie B, (6) Italian Serie C, and (7) Coppa Italia, the major Italian domestic cup competition. ${ }^{5}$ This rich data set contains a heterogeneous mix of matches, played in both domestic and European cup competition and involves teams with a range of abilities.

We considered looking at a longer time period, i.e., since the end of WW2, but found that football matches behind closed doors in the major European professional football competitions were sporadic before 2002. In fact, to the best of our knowledge, the last game prior to 2002 in these competitions that took place without fans was in 1993 in Italy. We ignore the other three of the top five European football leagues, in England, in Germany and in Spain, because there were only two matches in these competitions since 2002 and before April 2020 without fans. We ignore football below the top league in France, as in the same time period we found only eight matches played behind closed doors in the second (Ligue 2) or third (Championnat National) tiers.

We decided to exclude all matches since the Covid-19 shutdown, after March 2020, from the main analysis here because the absence of the fans is not the only thing that changed across and within the different European leagues. Rules were temporarily altered to facilitate the completion of the 2019/20 domestic seasons in less time than was planned, such as on the number and timing of player substitutions within matches. Further, we would not be able to rule out that the virus itself, or the break from training and competition that it caused, affected match outcomes and home advantage. For example, it is plausible that fatigue from a lack of training and more frequent fixtures could interact with travel fatigue to increase home advantage.

Figure 2 shows the distribution of the studied closed doors matches over competitions and seasons. There were just 160 matches that had no fans present since 2002, out of a total of 33,796 after excluding those that took place in neutral stadiums, such as the UEFA competition finals. Overall in the sample, this is a rate of $0.47 \%$ matches played in empty stadiums: $0.67 \%$ (38 matches) in the UEFA competitions, $0.52 \%$ (34 matches) in Serie A, 0.47\% (69 matches) in other Italian football, and $0.28 \%$ (19 matches) in Ligue 1. As Figure 2 shows, around $40 \%$ of the closed doors

\footnotetext{
${ }^{5}$ Excludes the qualifying stages of the UEFA competitions, but the Coppa Italia is included from round 1 onward.
} 
matches took place in just two seasons, 2006/07 and 2019/20. Italy accounted for most of these matches. The first cluster of games without fans followed from the Italian Calciopoli scandal, which was previously studied by PLP. The second cluster of games took place in 2020, just before the the Covid-19 virus lockdowns and bans on professional sports. As such, Italian football dominates our sample of closed doors matches, but almost a quarter took place in the UEFA competitions, and there were nineteen in the French Ligue 1.

FIGURE 2: Sample number of closed doors matches by season and competition/country

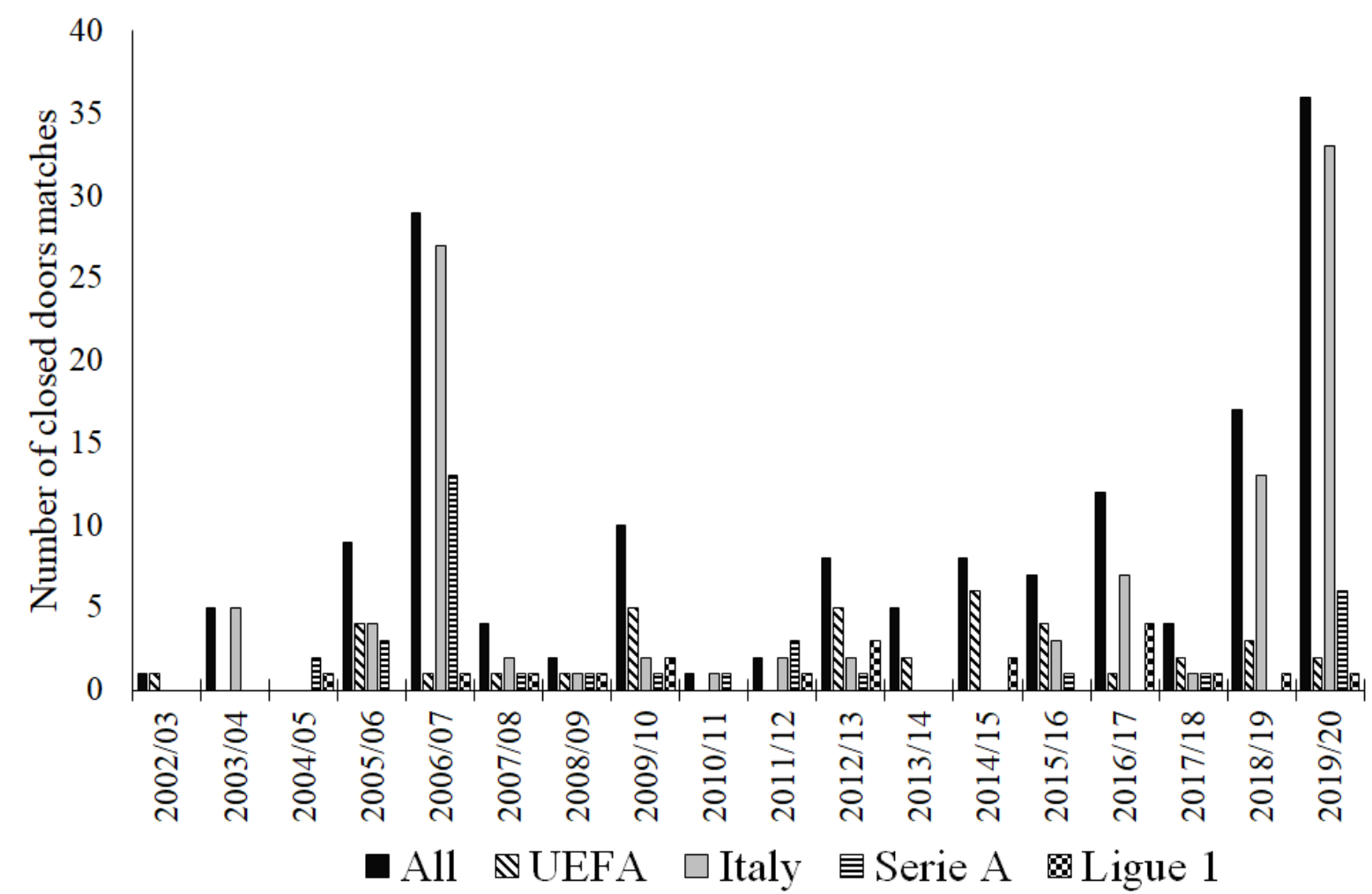

Notes.- "All" refers to all competitions in the sample. "UEFA" refers to matches in the UEFA Champions League, Europa League and their previous iterations under different names. "Italy" refers to matches in Serie A, Serie B, Serie C and Coppa Italia. "Serie A" refers to the Italian Serie A only. "Ligue 1" refers to the French Ligue 1. Source.worldfootball.net; accessed 14 March 2020.

We collected data on what happened within these football matches and their final outcomes from two data sources: (1) worldfootball.net and (2) espn.co.uk/football. Table 2 presents descriptive statistics over all 33,796 matches. The data represent 458 different teams playing at home and 581 different teams playing away from home. They correspond to 13,993 distinct matchups between specific home and away teams, e.g., Juventus F.C. playing at home in Turin against A.C. Milan. ${ }^{6}$

\footnotetext{
${ }^{6} \mathrm{We}$ discard and never describe all matches where the team playing at home only appeared once in the respective sub-group in a season, because in the regression analysis that follows we at least account for home-team-season fixed effects. For example, if an Italian Serie D team lost at home in the first round of the Coppa Italia, then that match would be discarded.
} 
We also know the identity of the 701 different referees who officiated these matches. Table 2 , shows that attendances in professional European football were quite variable in this period, ranging from zero in matches played behind closed doors to a maximum of 98,800 at FC Barcelona's Camp Nou. Attendances were on average higher and more variable in the UEFA competitions than the domestic leagues, though the Elite matches still had a respectable median attendance of 18,200. The matches studied in Italy typically had lower attendances than the rest of the sample, because the lower leagues and Coppa Italia generally attracted fewer fans (Online Appendix Table B1).

Table 2 summarises the Elo (1978) ratings of the home and away teams represented in the study. These are time-varying measures of each team's relative strengths, and are a function of the entire history of European domestic and continental professional football result outcomes scraped from worldfootball.net. They also capture the recent form of teams, as the recursive updating of the ratings after each match weights those completed more recently more highly. ${ }^{7}$ The Elo ratings will be useful control variables in the following regression analysis. Elo ratings were typically lower in the Italian domestic sub-sample, and they were on average higher in the Elite leagues than in the UEFA competitions (Online Appendix Table B1). The latter involved teams from countries with weaker domestic leagues than in Italy and France.

It is well-known that home advantage is substantial in professional football. Table 2 shows that in all the matches considered here since $2002,46 \%$ ended in a home win, $28 \%$ in a draw and $26 \%$ in an away win. The home advantage has tended to be greater in the UEFA competitions than in domestic football and was marginally greater at the Elite level than in Italy overall, when including the lower-league teams (Online Appendix Table B2). These patterns across the competitions were also reflected in the average goal difference between the home and away teams, which was 0.4 goals in the whole sample and had a median value in all the competitions of zero.

When a referee determines that there has been foul play in a football match, in addition to awarding a free-kick to the team that was fouled, there are three more serious ways that he can decide to punish players and teams. First, he/she can award a yellow card to a player, also know as a caution. Cumulative yellow cards over matches can result in players becoming suspended. If a

\footnotetext{
${ }^{7}$ Elo ratings, originally proposed by Elo (1978) for chess players and tournaments, are commonly used to estimate the strengths and form of football teams, both in practical applications (e.g., https://www.eloratings.net/) and in academic research (e.g., Hvattum and Arntzen, 2010).
} 
TABLE 2: Summary statistics over football matches, 2002-2020

\begin{tabular}{|c|c|c|c|c|c|}
\hline & Mean & St. Dev. & Min. & Median & Max. \\
\hline \multicolumn{6}{|l|}{ All } \\
\hline Attendance (1000s) & 16.0 & 15.9 & 0.0 & 11.1 & 98.8 \\
\hline Home Elo rating & 1085 & 107 & 732 & 1076 & 1532 \\
\hline Away Elo rating & 1079 & 107 & 741 & 1069 & 1517 \\
\hline Home win $(\%)$ & 45.8 & & & & \\
\hline Draw $(\%)$ & 28.2 & & & & \\
\hline Away win (\%) & 26.0 & & & & \\
\hline Goal diff. (Home-Away) & 0.40 & 1.62 & -9 & 0 & 15 \\
\hline Total yellow cards & 4.21 & 1.98 & 0 & 4 & 13 \\
\hline Home yellow cards & 1.94 & 1.25 & 0 & 2 & 8 \\
\hline Away yellow cards & 2.28 & 1.31 & 0 & 2 & 8 \\
\hline Yellows diff. (Home-Away) & -0.34 & 1.64 & -7 & 0 & 7 \\
\hline Home red cards & 0.12 & 0.35 & 0 & 0 & 3 \\
\hline Away red cards & 0.17 & 0.41 & 0 & 0 & 4 \\
\hline Home penalty kicks & 0.11 & 0.34 & 0 & 0 & 3 \\
\hline Away penalty kicks & 0.07 & 0.27 & 0 & 0 & 3 \\
\hline Penalties missed (\%) & 21 & 40 & 0 & 0 & 100 \\
\hline$N$ of home teams & & & 458 & & \\
\hline$N$ of away teams & & & 581 & & \\
\hline$N$ of home-away team pairs & & & 13,993 & & \\
\hline$N$ of referees & & & 701 & & \\
\hline$N$ of matches & & & 33,796 & & \\
\hline$N$ behind closed doors & & & 160 & & \\
\hline
\end{tabular}

Notes.- statistics are calculated over all matches in the analysis sample since the beginning of the 2002/03 season to April 2020. Excludes matches where the home team appeared only once in a competition in a given season. See Online Appendix Tables B1 \& B2 for summary statistics by competition. Source.- worldfootball.net; accessed 14 March 2020.

player is awarded two yellow cards in the same match, then he/she is excluded from the remainder of the match, meaning that their team must finish the match at a significant disadvantage to the opponent, with one player fewer. Second, the referee can award a straight red card to a player for serious foul play, resulting in a direct exclusion. Third, if a foul is committed by a team in their own penalty area, then the referee will award a penalty kick to the opposing team. A penalty is a significant punishment in football, since the game is generally low-scoring and it results in a goal $79 \%$ of the time in our sample. ${ }^{8}$ Table 2 shows sample statistics for these three punishments. On average, 4.2 yellow cards were awarded per match, with more cards in Italy than in European

\footnotetext{
${ }^{8}$ With this in mind, when an apparent foul in the penalty area isn't awarded by the referee, it is often said by football match commentators and fans: "if that were anywhere else on the pitch, then it would have been a foul", i.e., the implications of awarding a penalty kick suggestively make the referee think twice about awarding a foul. The same is also often said about a referee's decision to award a second yellow card for foul play or not, i.e., the necessary severity of a foul to warrant a second yellow is typically higher.
} 
competition (Online Appendix Table B2). The standard deviation of yellow cards per match was around two. On average, approximately a third of a yellow card more was awarded to the away teams than the home teams in our sample. Depending on the competition, a red card, both straight and via two yellows, was awarded every three to five matches, being rarer in the UEFA competitions than in domestic football. Like yellow cards, red cards were more frequently awarded to away teams. On average, a penalty was awarded in around one in five matches, and was also more likely to be awarded in favour of the home team. These penalties were missed (i.e., not scored) substantially more often in the UEFA matches (31\%) than in Italy (18\%) and at the Elite domestic level (24\%) (Online Appendix Table B2).

For a sub-sample of the matches described in Table 2, namely most of those in the UEFA and Elite sub-samples, we have information on other match features from espn.co.uk/football: the numbers of fouls committed; injury time allowed by the referee and played at the end of the first and second halves, along with the match scoreline at the time; the share of ball possession by the home team; total shots on goal by each team, including the numbers on target; and the numbers of saves made by goalkeepers. Before estimating any regression models, in Online Appendix A, we compare the sample means of all the outcomes described so far between matches played with fans and without, across all 33,796 matches in the sample, since the beginning of the 2002/03 season and up to the Covid-19 induced shutdown of professional football by the end of March 2020. These descriptive results suggest that home advantage was significantly reduced in the pre-Covid-19 matches played behind closed doors: a reduced likelihood of a home win, fewer goals scored by the home team and smaller goal differences between teams, and fewer yellow cards awarded to the away team.

\section{ESTIMATION \& MAIN RESULTS}

The descriptive results in Online Appendix A are generated from comparing a small number of matches played behind closed doors with many others played in completely different circumstances: in different stadiums, between different teams and with different referees. It is possible that the factors leading to a match being played without fans are correlated with outcomes, preventing any causal interpretation of the results described so far. For example, some matches were played behind 
closed doors as a punishment for racial abuse by home fans. ${ }^{9}$ These instances may have been driven by the rivalry or competitiveness between particular teams, which not only could have affected final match outcomes but also the amount of foul play within matches. In the next section, we attempt to overcome these issues and arrive at more robust and plausibly causal estimates for the effects of playing without crowds on football match outcomes, punishments and foul play.

\section{IV.i Empirical strategy}

The ideal experiment to test the impacts of playing football without fans would involve repeating the same matches many times, with the same players, officials and conditions, only varying whether or not spectators were allowed into the stadium. But this is impractical, and so we apply panel data regression methods to the historical sample of matches described above, to get as close as possible to the ideal experiment. We do this in three steps.

First, we select a "control" sample of football matches for each one that was played behind closed doors. Football teams play each other in the same locations on a regular basis. We use this fact, and select alongside each closed doors match only the same matchups (teams and location) that took place in the same calendar year, either of the previous two calendar years, or either of the following two calendar years. 97 of the total 160 matches without fans have at least one "control" in the sample: 1 has 5,11 have 4, 12 have 3, 25 have 2 and 48 have 1, overall giving a total of 183 "control" matches. Table 3 shows that only 7 of the closed doors matches that have at least one "control" match took place in UEFA competitions, 17 in French Ligue 1, 30 in Italian Serie A, and the remainder in other Italian domestic football. This is the sample of matches that we select and focus on in the remainder of this section, although later we also provide a robustness check using only the most recent "control" observation that took place before a closed doors match in the same or previous two calendar years.

A naïve empirical strategy would use this selected sample of 280 matches to estimate the following using least squares:

$$
y_{i}=\alpha+\lambda \text { ClosedDoors }_{i}+\varepsilon_{i},
$$

\footnotetext{
${ }^{9}$ For instance, Juventus F.C. were ordered to play a match behind closed doors after their fans racially abused an Inter Milan player in Italy’s Serie A; see http://news.bbc.co.uk/sport1/hi/football/europe/8008928.stm.
} 
TABLE 3: Numbers of matches in the total and matched estimation samples by competition

\begin{tabular}{lcccc}
\hline & Total & $\begin{array}{c}\text { Total behind } \\
\text { closed doors }\end{array}$ & $\begin{array}{c}\text { Matched } \\
\text { behind closed } \\
\text { doors }\end{array}$ & $\begin{array}{c}\text { Matched with } \\
\text { fans }\end{array}$ \\
\hline UEFA Champions League & 2,244 & 13 & 3 & 4 \\
UEFA Europa Leauge & 3,440 & 25 & 4 & 3 \\
French Ligue 1 & 6,735 & 19 & 17 & 38 \\
Italian Seria A & 6,566 & 34 & 30 & 66 \\
Coppa Italia & 743 & 3 & 1 & 4 \\
Italian Serie B & 7,942 & 38 & 24 & 40 \\
Italian Serie C & 6,126 & 28 & 18 & 28 \\
Total & 33,796 & 160 & 97 & 183 \\
\hline
\end{tabular}

Notes. " Matched" refers to the numbers of matches in the "Total" sample, where for a given match played behind closed doors at least one match involving the same two teams playing in the same location was found to have taken place in the same calendar year or any of the previous or following two calendar years.

where $y_{i}$ is the variable of interest for match $i, \alpha$ is a constant, ClosedDoors $s_{i}$ is a dummy variable equal to one if a match was played behind closed doors, and $\varepsilon_{i}$ is the error term. Estimates of $\lambda$ could then be interpreted somewhat loosely as the causal effects of playing a match behind closed doors on $y$. However, there are some obvious omitted variables from this regression model. In our relatively small selected sample of matches, without perfectly random assignment of which matches were played behind closed doors, we should control for other factors that may significantly affect $y_{i}$, such as the within season strengths and form of the teams involved. There is also the possibility that the assignment of referees to closed doors matches is non-random. For example, matches without fans may carry a higher profile or be more contentious, which may result in the assignment of a more experienced referee, who is less affected by the presence or not of a crowd. To address these possible confounding factors, we employ a two-step regression approach, which are thus the second and third steps of our empirical strategy.

In the first-step regression, for each variable of interest $\left(y_{i}\right)$ we use all 33,796 matches described in Section III and Online Appendix A to estimate the following using least squares: ${ }^{10}$

$$
y_{i}=\delta_{1} \text { HomeElo }_{i}+\delta_{2} \text { AwayElo }_{i}+\psi_{H S(i)}+\phi_{A S(i)}+\kappa_{R(i)}+\eta_{i}
$$

\footnotetext{
${ }^{10}$ After dropping singleton observations from the estimation samples, for example because a referee only appeared once, we actually use 33,284 matches.
} 
where HomeElo $\mathrm{H}_{i}$ and AwayElo $i$ are controls for the match-by-match-varying strengths and form of both the home and away teams, via Elo ratings, with coefficients $\delta_{1}$ and $\delta_{2}$. The regression model also includes fixed effects for both the home-team-season $\left(\psi_{H S(i)}\right)$, and the away-team-season $\left(\phi_{A S(i)}\right)$, where $H S(i)$ and $A S(i)$ are functions indicating that match $i$ took place in season $s$ and involved home team $h$ or away team $a$. These variables account for across season differences in team abilities and strengths when playing home or away. ${ }^{11}$ We control for average referee heterogeneity in decision-making or the conveyance of a home advantage with fixed effects $\left(\kappa_{R(i)}\right)$, where $R(i)$ is an indicator function that match $i$ took place with referee $r$ adjudicating. $\eta_{i}$ is the residual. We considered variables reflecting the timing and scheduling of matches in Equation (1) as predictors, but generally found that these were insignificant after accounting for the Elo ratings and the three sets of fixed effects.

In the second-step regression and third step of our overall empirical strategy, we collect the predicted values from Equation (1), $\widehat{y}_{i}$, for the sample of 280 matches selected in the first step, and use this as a control variable:

$$
y_{i}=\alpha+\lambda \text { ClosedDoors }_{i}+\beta \widehat{y}_{i}+\varepsilon_{i} .
$$

We can be relatively more confident interpreting the estimates of $\lambda$ from Equation (2) as the causal effects of playing behind closed doors on match outcomes. Our selection of "control" matches means that we are comparing matches with and without fans that have the same major characteristics. To make this distinction even clearer, in what follows, we also present estimates of Equation (2) with the addition of matchup fixed effects, thus further addressing the average heterogeneity in outcomes specific to the home and away teams and locations (e.g., it could be that matches between A.S. Roma and SS Lazio are typically ill-tempered affairs with many cards awarded, regardless of whether any fans were present). Further, our two-step regression approach goes some way to address concerns that the assignment of a match to closed doors was non-random, as well as accounting for the selection of referee characteristics into these matches. One potential confounding variable is the introduction and operation of VAR technology in the later years of the estimation sample, which

\footnotetext{
${ }^{11}$ This is also akin to how home advantage in sports league is normally estimated (e.g., Clarke and Norman, 1995).
} 
may have affected match outcomes and referee bias (e.g., Albanese et al., 2020). ${ }^{12}$ We considered adding a dummy variable to the model for whether VAR was in operation, as well as its interaction with ClosedDoors $s_{i}$, but found these to have statistically insignificant effects on all of the dependent variables that we look at. We estimate Equation (2) with standard errors robust to matchup clusters, because of how we selected the sample of matches in step one. ${ }^{13}$ In the following tables of results, we also show estimates of the comparable one-step regression model, by including ClosedDoors $s_{i}$ in Equation (1), which tends to attenuate the effect estimates, probably due to the "control" groups of matches then being larger but less relevant (i.e., further away in time) from the matches played without fans in the stadium.

We study the following dependent variables $\left(y_{i}\right)$ in Equations (1) and (2): the result outcome, goal difference, home and away yellow cards received, yellow card difference, home and away fouls committed, and yellow cards per foul. ${ }^{14}$ For the result outcome, we code the dependent variable as $\{1,0.5,0\}$ corresponding to $\{$ Home win, Draw, Away win $\}$, such that the least squares estimates can be interpreted in effect as a linear probability model for the home win. ${ }^{15}$ For the counts of home and away yellow cards and fouls, we estimate the Poisson regression equivalent of Equation (2). As Online Appendix Figure A2 suggests and diagnostic checks later confirm, the Poisson regression is well-justified. For the differences in yellow cards (per foul) and goals scored in matches, we treat these as quasi-continuous and use least squares to estimate Equation (2). We prefer to estimate the linear models given by Equation (2) rather than, for example, an ordered latent variable model for the result outcome, because we are focused on the average marginal effects of playing a match behind closed doors, and the models control for a lot of unobserved heterogeneity with the different sets of fixed effects (see Wooldridge, 2010, for discussion on these issues). ${ }^{16}$

\footnotetext{
${ }^{12}$ VAR was introduced in the competitions as follows: Champions League, February 2019; Europa League, February 2020; Serie A, 2017/18 season; Coppa Italia, January 2018; Serie B, January 2020; Ligue-1, 2018/19 season.

${ }^{13}$ We also considered block bootstrapping over matchups to estimate the standard errors, which produced marginally narrower confidence intervals.

${ }^{14}$ Unfortunately, we do not have information on the nature of the foul play. Several offences can justify a yellow card in football, and aggression has a broad meaning in the rules of the game, not only consisting of single or cumulative bad tackles but also shirt pulling, time wasting, dissent aimed at the referee etc.

${ }^{15}$ The match result model can be interpreted as a linear probability model for the home win, but it is also equivalent to having the points gap between the home and away team as the dependent variable, where the winning team in football is awarded three points, and one point is awarded to both teams in the case of a draw (i.e., $y_{i}=\{3,0,-3\}=\{$ Home win, Draw, Away win\}.

${ }^{16}$ We considered a Skellam distribution for the differences between two dependent Poisson random variables (see Karlis and Ntzoufras, 2003), such as yellow cards for home and away teams, but this offered no overriding benefits to estimate the marginal effects of interest.
} 


\section{IV.ii Estimation results}

Table 4 shows least squares regression estimates of Equation (2), with the goal difference between teams as the dependent variable. ${ }^{17}$ Column (I) gives the naïve estimates of the closed doors effect $(\widehat{\lambda})$, column (II) gives the two-step estimates, and column (III) adds the matchup fixed effects. Column (IV) shows the comparable one-step regression model estimates. The results suggest that home advantage is reduced when matches are played without fans, but not significantly, and also less so in the models that address the potentially endogenous assignment of closed doors football. These results are all reflected in Online Appendix Table B4, which shows the equivalent estimates for the match result or points gap outcome. Despite the apparent reduction in final match outcome home advantage in empty stadiums, when aggregating and pooling matches (Online Appendix Figure A1), this does not stand up to more careful statistical examination. This is the same conclusion reached by Bryson et al. (2021) from studying what happened to football matches around the world without crowds after the Covid-19 induced lockdowns and shutouts.

Table 5 shows the estimated effects of playing behind closed doors on the difference between the numbers of yellow cards awarded to the home and away teams within matches. The naïve estimate is a significant increase in this difference of almost half a card (column (I); $p$-value $<0.05)$, reducing the home advantage in punishments. After addressing the potential endogenous assignment of matches to the "treatment" in our selected sample, this estimate decreases to just over a third of a card (column (II); $p$-value $<0.1$ ), and after addressing fixed matchup-specific heterogeneity in column (III), the estimate of $\lambda$ becomes insignificant from zero. In Table 6 , we present the comparable Poisson regression estimates separately for the numbers of cards awarded to the home and away teams. Across all three model specifications, there is no reduction in the incidence of yellow cards awarded to the home team when a match is played without a crowd in the stadium. The reduced home advantage in punishments behind closed doors is instead accounted for by around 80 percent as many yellow cards being awarded to the away team. This estimated effect is significant ( $p$-value $<0.01$ ) and robust to both the two-step method and the inclusion of matchup fixed effects in the model. Online Appendix Tables B8-B10 show model estimates for sub-samples of the closed doors matches, showing that the effects were generally weaker in the small sample of pre-Covid-19

\footnotetext{
${ }^{17}$ The first-step regression model estimates for each dependent variable considered as $y_{i}$ are are shown in Online Appendix Table B3.
} 
matches but stronger among matches in Italy during 2006/07 season after the Calciopoli scandal, as studied previously by PLP.

TABLE 4: Regression model estimates for the effect of playing matches behind closed doors on goal differences (home minus away), 2002-2020

\begin{tabular}{lcccc}
\hline & $(\mathrm{I})$ & $(\mathrm{II})$ & $(\mathrm{III})$ & $(\mathrm{IV})$ \\
\hline Constant $(\widehat{\alpha})$ & $0.235^{* *}$ & -0.028 & -0.030 & \\
& $(0.116)$ & $(0.098)$ & $(0.052)$ & \\
Closed doors $(\widehat{\lambda})$ & -0.235 & -0.127 & -0.131 & -0.146 \\
& $(0.167)$ & $(0.143)$ & $(0.139)$ & $(0.137)$ \\
First-step predicted outcome $(\widehat{\beta})$ & & $0.919^{* * *}$ & $0.932^{* * *}$ & \\
& & $(0.090)$ & $(0.128)$ & \\
\hline Matchup fixed effects & No & No & Yes & No \\
$R^{2}$ & 0.006 & 0.274 & 0.581 & 0.357 \\
$N$ of matches & 280 & 280 & 280 & 33,284 \\
$N$ of matchups/closed doors matches & 97 & 97 & 97 & 160 \\
\hline
\end{tabular}

Notes.- $* * *, * * *$ indicate significance from zero at $1 \%, 5 \%$ and $10 \%$ levels, respectively, two-sided tests, standard errors in parentheses are robust to matchup clusters in all models. Columns (I)-(III) show linear regression estimates of Equation (2), where the dependent variable is the difference between the numbers of goals scored by the home and away teams (home minus away). Column (IV) shows linear regression estimates of Equation (1) for the whole sample of matches for seasons 2002/03-19/20 described in Table 2, after dropping singletons, with an added dummy variable for closed doors matches, as well as Elo rating controls, home-team-season, away-team-season and referee fixed effects. Source.- author calculations using worldfootball.net and espn.co.uk/football; accessed 14 March 2020.

TABLE 5: Regression model estimates for the effect of playing matches behind closed doors on yellow card differences (home minus away), 2002-2020

\begin{tabular}{lcccc}
\hline & $(\mathrm{I})$ & $(\mathrm{II})$ & $(\mathrm{III})$ & (IV) \\
\hline Constant $(\widehat{\alpha})$ & $-0.268^{* *}$ & -0.074 & -0.013 & \\
& $(0.120)$ & $(0.099)$ & $(0.069)$ & \\
Closed doors $(\widehat{\lambda})$ & $0.464^{* *}$ & $0.346^{*}$ & 0.232 & $0.233^{*}$ \\
& $(0.213)$ & $(0.180)$ & $(0.187)$ & $(0.138)$ \\
First-step predicted outcome $(\widehat{\beta})$ & & $1.167^{* * *}$ & $1.322^{* * *}$ & \\
& & $(0.116)$ & $(0.143)$ & \\
\hline Matchup fixed effects & No & No & Yes & No \\
$R^{2}$ & 0.018 & 0.298 & 0.519 & 0.236 \\
$N$ of matches & 280 & 280 & 280 & 33,248 \\
$N$ of matchups/closed doors matches & 97 & 97 & 97 & 160 \\
\hline
\end{tabular}

Notes.- $* * *, * * *$ indicate significance from zero at $1 \%, 5 \%$ and $10 \%$ levels, respectively, two-sided tests, standard errors in parentheses are robust to matchup clusters. Columns (I)-(III) show linear regression estimates of Equation (2), where the dependent variable is the difference between the numbers of yellow cards awarded to the home and away teams (home minus away). Column (IV) shows linear regression estimates of Equation (1) for the whole sample of matches for seasons 2002/03-19/20 described in Table 2, dropping singletons, with an added dummy variable for closed doors matches, as well as Elo rating controls, home-team-season, away-team-season and referee fixed effects. Source.- author calculations using worldfootball.net and espn.co.uk/football; accessed 14 March 2020. 
Our selection of "control" matches into the estimation sample for Equation 2 could be viewed as somewhat arbitrary. Therefore, we check the robustness of our results to using a more restricted selection of matches. First, we ignore all potential "control" matches when they took place at any time after their closed doors counterpart. Second, we only pair closed doors matches with the most recent "control" match taking place in the same or the previous two calendar years. This leads to a reduced sample of 79 closed doors matches, each with just one paired "control" match (5 in UEFA competitions, 12 in French Ligue 1, 21 in Italian Serie A, and 41 in other Italian domestic football). Online Appendix Tables B5-B7 show the estimation results using this smaller sample which are equivalent to those described above in Tables 4-6. We find that all the main results are qualitatively and approximately quantitatively robust to these two different selections of closed doors and "control" matches into the estimation samples.

As described in Sections III and IV, for a sub-sample of matches in the dataset we know the number of fouls awarded by referees. Applying our preferred empirical strategy for this sub-sample, Table 7 shows estimates for the effect of playing behind closed doors on the difference between home and away teams in the numbers of yellow cards awarded per foul committed. The naïve estimate is an increase of 0.044 cards per foul, is smaller at 0.040 in the two-step least squares model, and is smaller still at 0.035 with the added matchup fixed effects, but all these estimates are significantly different from no effect. For this smaller sample of matches, therefore, we can confirm that the reduced home advantage in punishments behind closed doors is driven by changed card giving for the away team rather than changes to the amount of foul play in matches. This is further confirmed by the results in Online Appendix Tables B11 and B12, which show separate model estimates for home and away teams, with the dependent variables in the tables being the numbers of fouls and yellow cards per foul, respectively. For example, column (III) of Online Appendix Table B11 shows an empty stadium decrease of one yellow card for every twenty-two fouls committed by the away team $(p$-value $<0.01)$.

These results, and their suggestion of how referee bias interacts with a football crowd, do not dovetail perfectly with what PLP found in just twenty-one matches in empty Italian stadiums in 2006/07. PLP found significantly fewer yellow cards awarded to both the home and the away teams without fans, with the difference between them narrowing, as well as significantly fewer fouls awarded against the away team. By increasing the sample of closed doors matches here, 
TABLE 6: Poisson regression estimates (incident rate ratio) for the effect of playing matches behind closed doors on home and away yellow cards, 2002-2020

\begin{tabular}{|c|c|c|c|c|c|c|}
\hline & \multicolumn{3}{|c|}{ Home cards } & \multicolumn{3}{|c|}{ Away cards } \\
\hline & (I) & (II) & (III) & (IV) & (V) & (VI) \\
\hline Constant $(\widehat{\alpha})$ & $\begin{array}{c}2.071^{* * *} \\
(0.093)\end{array}$ & $\begin{array}{c}0.641^{* * *} \\
(0.071)\end{array}$ & $\begin{array}{c}0.582^{* * *} \\
(0.098)\end{array}$ & $\begin{array}{c}2.339^{* * *} \\
(0.085)\end{array}$ & $\begin{array}{c}0.908 \\
(0.125)\end{array}$ & $\begin{array}{c}0.975 \\
(0.147)\end{array}$ \\
\hline Closed doors $(\widehat{\lambda})$ & $\begin{array}{c}0.990 \\
(0.073)\end{array}$ & $\begin{array}{c}0.951 \\
(0.059)\end{array}$ & $\begin{array}{c}0.903 \\
(0.060)\end{array}$ & $\begin{array}{c}0.793^{* * *} \\
(0.059)\end{array}$ & $\begin{array}{c}0.796^{* * *} \\
(0.054)\end{array}$ & $\begin{array}{c}0.808^{* * *} \\
(0.057)\end{array}$ \\
\hline First-step predicted outcome $(\widehat{\beta})$ & & $\begin{array}{c}1.669^{* * *} \\
(0.069)\end{array}$ & $\begin{array}{c}1.780^{* * *} \\
(0.122)\end{array}$ & & $\begin{array}{c}1.484^{* * *} \\
(0.079)\end{array}$ & $\begin{array}{c}1.463^{* * *} \\
(0.088)\end{array}$ \\
\hline Matchup fixed effects & No & No & Yes & No & No & Yes \\
\hline Log pseudol'hood & -463.8 & -426.2 & -401.4 & -446.6 & -430.9 & -405.9 \\
\hline Pearson $\chi^{2}$ test, $p$-value & 0.993 & 1.000 & & 1.000 & 1.000 & \\
\hline Log l'hood ratio test, $p$-value & 0.623 & 1.000 & & 1.000 & 1.000 & \\
\hline$N$ of matches & 280 & 280 & 278 & 280 & 280 & 280 \\
\hline$N$ of matchups/closed doors matches & 97 & 97 & 96 & 97 & 97 & 97 \\
\hline
\end{tabular}

Notes.- $* * * * * * *$ indicate significance from one at $1 \%, 5 \%$ and $10 \%$ levels, respectively, two-sided tests, standard errors in parentheses are robust to matchup clusters. Columns (I)-(VI) display Poisson regression equivalent estimates of Equation (2), where the dependent variables are the numbers of yellow cards awarded to the home and away teams. Source.- author calculations using worldfootball.net and espn.co.uk/football; accessed 14 March 2020.

TABLE 7: Regression model estimates for the effect of playing matches behind closed doors on the difference in yellow cards per foul (home minus away), 2002-2020

\begin{tabular}{lcccc}
\hline & $(\mathrm{I})$ & $(\mathrm{II})$ & $(\mathrm{III})$ & $(\mathrm{IV})$ \\
\hline Constant $(\widehat{\alpha})$ & -0.020 & -0.019 & $-0.017^{* * *}$ & \\
& $(0.013)$ & $(0.012)$ & $(0.005)$ & \\
Closed doors $(\widehat{\lambda})$ & $0.044^{* *}$ & $0.040^{* *}$ & $0.035^{* *}$ & -0.002 \\
& $(0.021)$ & $(0.016)$ & $(0.016)$ & $(0.016)$ \\
First-step predicted outcome $(\widehat{\beta})$ & & $1.110^{* * *}$ & $1.298^{* * *}$ & \\
& & $(0.169)$ & $(0.166)$ & \\
\hline Matchup fixed effects & No & No & Yes & No \\
$R^{2}$ & 0.031 & 0.392 & 0.737 & 0.338 \\
$N$ of matches & 101 & 101 & 101 & 13,158 \\
$N$ of matchups/closed doors matches & 35 & 35 & 35 & 65 \\
\hline
\end{tabular}

Notes.- $* * *, * * *$ indicate significance from zero at $1 \%, 5 \%$ and $10 \%$ levels, respectively, two-sided tests, standard errors in parentheses are robust to matchup clusters. Columns (I)-(III) show linear regression estimates of Equation (2), where the dependent variable is the difference between the numbers of yellow cards awarded to the home and away teams per fouls committed (home minus away). Column (IV) shows linear regression estimates of Equation (1) for the whole sample of matches for seasons 2002/03-19/20 described in Table B1, dropping singletons, with an added dummy variable for closed doors matches, as well as Elo rating controls, home-team-season, away-team-season and referee fixed effects. Source.- author calculations using worldfootball.net and espn.co.uk/football; accessed 14 March 2020.

generalising to other competitions outside of Italy, and improving the empirical strategy to control for the selection of team and referee attributes into these matches, we find that only the negative impact of playing without fans on the number of yellow cards awarded to the away team is convincingly robust, including specifically in Italy during the 2006/07 season (see Online Appendix Tables B9 
\& B10). More so, we find no significant effects of playing without fans on the numbers of fouls committed in matches, which emphasises that a football crowd acts on home advantage primarily by affecting referee behaviour rather than the players.

Despite our concerns that football after Covid-19 may have been affected by more than just the absence of the stadium crowds, such as player fatigue and changes to official instructions for referees and players about their behaviour and punishments, the results in this section dovetail closely with what Bryson et al. (2021) estimated as the ghost games effects across almost 1,500 matches without stadium crowds in 23 leagues and 17 countries within the 2019/20 seasonSome of the pre-Covid-19 matches played behind closed doors took place that way due to punishments for bad behaviour by crowds. This bad behaviour could be correlated with particularly lively or vociferous crowds, which exert more than normal social pressure on football referees. It is reassuring then for the external validity of our results that the estimated effect in Bryson et al. (2021) of an empty stadium on the yellow card differences home and away teams for post-Covid-19 football was approximately the same as estimated here for pre-Covid-19, i.e., a third of a card per match.

After carefully addressing the endogeneity of closed doors football and the natural variance in football match outcomes, the lack of the normal home-team-supporting crowd reduces the bias of referees against the away team, but not significantly enough to affect final match outcomes.

\section{CONCLUDING REMARKS}

In this paper, we investigated the impact of social pressure on the outcomes of historical European football matches. We exploited the rare instances when professional and competitive matches were played behind closed doors, treating these as natural experiments, where the only factor varied was the presence or not of fans in the stadiums. After addressing the non-random process in which matches were assigned to be played behind closed doors, we found no significant effects on match results or scorelines. However, these estimated effects were consistently large in sports terms across variants of our model and sub-samples of the data, pointing towards reduced overall home advantage, and suggesting that with more natural experiments and statistical power no effect may have been rejected. But the standout effect of playing behind closed doors was the significantly decreased 
severity of punishments for the away team, mainly through the reduced number of yellow cards awarded. This suggests that the referee is normally affected by the social pressure of a predominantly home-team-supporting crowd, punishing the away team's players more severely. These results contribute to a wide literature that has also found evidence that home advantage in professional sports can in part be attributed to the unconscious bias of those officiating (e.g., Dohmen and Sauermann, 2016).

The results in this paper, added to the related studies of football after Covid-19 summarised in Section II, could have implications for the competitive balance of sports leagues and demand. Home advantage ensures that a weak team playing in its own stadium often has a good chance of beating a strong team (Forrest et al., 2005). If this effect is greater for weaker teams, then strong teams would win more often, and the competitive balance of leagues would be reduced. The evidence on the interaction between home advantage and team quality is limited. Bray et al. (2003) found in English football that home advantage in terms of wins was slightly greater for stronger teams, but weaker teams appeared to have a relatively greater advantage in earning draws at home. Rottenberg's (1956) "Uncertainty of Outcome Hypothesis", whereby sports demand increases the less certain is the outcome, has been shown to apply to football fans watching on television (e.g., Buraimo and Simmons, 2009; Cox, 2018; Schreyer et al., 2018a,b). This suggests that TV audience demand for league football could be affected for matches behind closed doors. Reduced home advantage should increase the attractiveness of matches featuring a strong home team and a weak away team, and vice versa when those relative strengths are reversed. In addition, there could be a second magnifying effect on demand, as changes in home advantage which are not equally distributed over team strengths would tend toward making the overall league championships more or less competitive, affecting the interest of fans. Despite our results, we should still be somewhat cautious in assuming that the reduction in home advantage observed in one-off historical matches behind closed doors transfers to the situation in professional sport after Covid-19, where empty stadiums became the norm. One potential explanation for home advantage is a team's familiarity with its surroundings. For example, there is evidence that sports teams who move to new stadiums only temporarily experience reduced home advantage (e.g., Pollard, 2002; Wilkinson and Pollard, 2006). Although our results suggest that the closed doors effect acts through the referees and their bias, this may diminish or alter if they and the other participants become accustomed to playing 
without spectators. More research is needed to unpick these issues, especially on whether the closed doors effect is greater for some teams than others, and what could determine any differences apart from heterogeneity over the referees assigned to matches.

From a behavioural perspective, ideally we would have isolated the actions of the different agents in a football match, i.e., the players, officials and managers, to identify more precisely the mechanisms through which outcomes are affected by playing behind closed doors. In the historical data considered here, this was not practical, as the small sample of matches without fans did not afford much statistical power. This is something that future research could look to address, exploiting the variation across leagues and countries in how European football was shocked and subsequently recovered from Covid-19. 


\section{References}

Akerlof, G. (1980). A Theory of Social Custom, of which Unemployment may be One Consequence. The Quarterly Journal of Economics 94(4), 749-775.

Albanese, A., S. Baert, and O. Verstraeten $(2020,02)$. Twelve eyes see more than eight. referee bias and the introduction of additional assistant referees in soccer. PLOS ONE 15(2), 1-15.

Almeida, C. H. and W. S. Leite (2021). Professional football in times of COVID-19: did the home advantage effect disappear in European domestic leagues? Biology of Sport 38(4), 693-701.

Balmer, N. J., A. M. Nevill, and A. M. Williams (2003). Modelling home advantage in the Summer Olympic Games. Journal of Sports Sciences 21(6), 469-478.

Bar-Eli, M., A. Krumer, and E. Morgulev (2020). Ask not what economics can do for sports - Ask what sports can do for economics. Journal of Behavioral and Experimental Economics 89. 101597.

Becker, G. S. and K. M. Murphy (2000). Social Economics: Market Behavior in a Social Environment. Harvard University Press.

Belchior, C. A. (2020). Fans and Match Results: Evidence From a Natural Experiment in Brazil. Journal of Sports Economics 21(7), 663-687.

Benz, L. S. and M. J. Lopez (2021). Estimating the change in soccer's home advantage during the Covid-19 pandemic using bivariate Poisson regression. AStA Advances in Statistical Analysis.

Bernheim, B. D. (1994). A Theory of Conformity. Journal of Political Economy 102(5), 841-77.

Böheim, R., D. Grübl, and M. Lackner (2019). Choking under pressure - Evidence of the causal effect of audience size on performance. Journal of Economic Behavior \& Organization 168, 76-93.

Boudreaux, C. J., S. D. Sanders, and B. Walia (2017). A Natural Experiment to Determine the Crowd Effect Upon Home Court Advantage. Journal of Sports Economics 18(7), 737-749.

Bray, S. R., J. Law, and J. Foyle (2003). Team Quality and Game Location Effects in English Professional Soccer. Journal of Sport Behavior 26(4), 319-334.

Bryson, A., P. Dolton, J. J. Reade, D. Schreyer, and C. Singleton (2021). Causal effects of an absent crowd on performances and refereeing decisions during Covid-19. Economics Letters 198. 109664.

Buraimo, B., D. Forrest, and R. Simmons (2010). The 12th man?: refereeing bias in English and German soccer. Journal of the Royal Statistical Society: Series A (Statistics in Society) 173(2), 431-449.

Buraimo, B. and R. Simmons (2009). A tale of two audiences: Spectators, television viewers and outcome uncertainty in Spanish football. Journal of Economics and Business 61(4), 326-338.

Buraimo, B., R. Simmons, and M. Maciaszczyk (2012). Favoritism and referee bias in European soccer: Evidence from the Spanish League and the UEFA Champions League. Contemporary Economic Policy 30(3), 329-343.

Charness, G., L. Rigotti, and A. Rustichini (2007). Individual Behavior and Group Membership. American Economic Review 97(4), 1340-1352.

Charness, G. and M. Sutter (2012, September). Groups Make Better Self-Interested Decisions. Journal of Economic Perspectives 26(3), 157-76.

Chun, S. and S. S. Park (2021, January). Home Advantage in Skeleton: Familiarity versus Crowd Support. Journal of Sports Economics 22(1), 3-26. 
Clarke, S. and J. Norman (1995). Home Ground Advantage of Individual Clubs in English Soccer. Journal of the Royal Statistical Society. Series D (The Statistician) 44(4), 509-521.

Colella, F., P. S. Dalton, and G. Giusti (2018). You'll Never Walk Alone: The Effect of Moral Support on Performance. CentER Discussion Paper Series No. 2018-026. https://dx.doi.org/10.2139/ssrn.3214533.

Correia-Oliveira, C. R. and V. A. Andrade-Souza (2021). Home advantage in soccer after the break due to COVID-19 pandemic: does crowd support matter? International Journal of Sport and Exercise Psychology, 1-12.

Courneya, K. S. and A. V. Carron (1992). The Home Advantage In Sport Competitions: A Literature Review. Journal of Sport and Exercise Psychology 14(1), 13-27.

Cox, A. (2018). Spectator Demand, Uncertainty of Results, and Public Interest. Journal of Sports Economics 19(1), 3-30.

Cueva, C. (2020). Animal Spirits in the Beautiful Game. Testing social pressure in professional football during the COVID-19 lockdown. OSF Preprints. https://doi.org/10.31219/osf.io/hczkj.

Dawson, P. and S. Dobson (2010). The influence of social pressure and nationality on individual decisions: Evidence from the behaviour of referees. Journal of Economic Psychology 31(2), 181-191.

Dawson, P., S. Dobson, J. Goddard, and J. Wilson (2007). Are football referees really biased and inconsistent?: evidence on the incidence of disciplinary sanction in the English Premier League. Journal of the Royal Statistical Society: Series A (Statistics in Society) 170(1), 231-250.

Dohmen, T. and J. Sauermann (2016). Referee Bias. Journal of Economic Surveys 30(4), 679-695.

Dohmen, T. J. (2008a). Do professionals choke under pressure? Journal of Economic Behavior \& Organization 65(3), 636-653.

Dohmen, T. J. (2008b, July). The Influence Of Social Forces: Evidence From The Behavior Of Football Referees. Economic Inquiry 46(3), 411-424.

Elo, A. E. (1978). The Rating of Chessplayers, Past and Present. London: Batsford.

Endrich, M. and T. Gesche (2020). Home-bias in referee decisions: Evidence from "Ghost Matches" during the Covid19-Pandemic. Economics Letters 197. 109621.

Ferraresi, M. and G. Gucciardi (2021). Who chokes on a penalty kick? Social environment and individual performance during Covid-19 times. Economics Letters 203(C), S0165176521001452.

Fischer, K. and J. Haucap (2021). Does Crowd Support Drive the Home Advantage in Professional Football? Evidence from German Ghost Games during the COVID-19 Pandemic. Journal of Sports Economics 0(0), 15270025211026552. https://doi.org/10.1177/15270025211026552.

Forrest, D., J. Beaumont, J. Goddard, and R. Simmons (2005, April). Home Advantage and the Debate About Competitive Balance in Professional Sports Leagues. Journal of Sports Sciences 23(4), 439-445.

Garicano, L., I. Palacios-Huerta, and C. Prendergast (2005). Favouritism Under Social Pressure. The Review of Economics and Statistics 87(2), 208-216.

Goller, D. and A. Krumer (2020). Let's meet as usual: Do games played on non-frequent days differ? Evidence from top European soccer leagues. European Journal of Operational Research 286(2), 740-754.

Goumas, C. (2014). Home advantage and referee bias in European football. European Journal of Sport Science 14(sup1), S243-S249. PMID: 24444213. 
Guérette, J., C. Blais, and D. Fiset (2021). The absence of fans removes the home advantage associated with penalties called by National Hockey League referees. Plos one 16(8), e0256568.

Harb-Wu, K. and A. Krumer (2019). Choking under pressure in front of a supportive audience: Evidence from professional biathlon. Journal of Economic Behavior \& Organization 166, 246-262.

Hill, Y. and N. W. Van Yperen (2021). Losing the home field advantage when playing behind closed doors during COVID-19: Change or chance? Frontiers in Psychology 12.

Hvattum, L. M. and H. Arntzen (2010). Using ELO ratings for match result prediction in association football. International Journal of Forecasting 26(3), 460-470.

Jane, W.-J. (2021). Choking or excelling under pressure: Evidence of the causal effect of audience size on performance, journal = Bulletin of Economic Research.

Karlis, D. and I. Ntzoufras (2003). Analysis of sports data by using bivariate Poisson models. Journal of the Royal Statistical Society: Series D (The Statistician) 52(3), 381-393.

Leitner, M. C. and F. Richlan (2021). No Fans-No Pressure: Referees in Professional Football During the COVID-19 Pandemic. Frontiers in Sports and Active Living, 221.

Link, D. and G. Anzer (2021). How the COVID-19 Pandemic has Changed the Game of Soccer. International Journal of Sports Medicine.

Losak, J. M. and J. Sabel (2021). Baseball Home Field Advantage Without Fans in the Stands. International Journal of Sport Finance 16(3).

Matos, R., D. Monteiro, R. Antunes, D. Mendes, J. Botas, J. Clemente, and N. Amaro (2021). Home-Advantage during COVID-19: An Analysis in Portuguese Football League. International Journal of Environmental Research and Public Health 18(7), 3761.

McCarrick, D., M. Bilalic, N. Neave, and S. Wolfson (2021). Home advantage during the COVID-19 pandemic: Analyses of European football leagues. Psychology of Sport and Exercise 56, 102013.

Nevill, A., N. Balmer, and A. Williams (2002). The influence of crowd noise and experience upon refereeing decisions in football. Psychology of Sport and Exercise 3(4), 261-272.

Nevill, A. M. and R. L. Holder (1999). Home Advantage in Sport: An Overview of Studies on the Advantage of Playing at Home. Sports Medicine 28(4), 221-236.

Page, K. and L. Page (2010). Alone against the crowd: Individual differences in referees' ability to cope under pressure. Journal of Economic Psychology 31(2), 192-199.

Peeters, T. and J. C. van Ours (2021). Seasonal Home Advantage in English Professional Football; 1973-2018. De Economist 169, 107-126.

Pettersson-Lidbom, P. and M. Priks (2010). Behavior under social pressure: Empty Italian stadiums and referee bias. Economics Letters 108(2), 212-214.

Pollard, R. (2002). Evidence of a reduced home advantage when a team moves to a new stadium. Journal of Sports Sciences 20(12), 969-973.

Pollard, R. and G. Pollard (2005). Long-term trends in home advantage in professional team sports in North America and England (1876-2003). Journal of Sports Sciences 23(4), 337-350.

Ponzo, M. and V. Scoppa (2018). Does the Home Advantage Depend on Crowd Support? Evidence From Same-Stadium Derbies. Journal of Sports Economics 19(4), 562-582. 
Ramchandani, G. and R. Millar (2021). Investigating the "Twelfth Man" Effect in Five European Domestic Football Leagues: A COVID-19 Induced Natural Experiment. Journal of Global Sport Management.

Reade, J. J., D. Schreyer, and C. Singleton (2020a, June). Echoes: what happens when football is played behind closed doors? Economics Discussion Papers em-dp2020-14, Department of Economics, Reading University. https://dx.doi.org/10.2139/ssrn.3630130.

Reade, J. J., D. Schreyer, and C. Singleton (2020b). Stadium attendance demand during the COVID-19 crisis: early empirical evidence from Belarus. Applied Economics Letters O(0), 1-6. https://doi.org/10.1080/13504851.2020.1830933.

Rocha, B., F. Sanches, I. Souza, and J. C. D. da Silva (2013). Does monitoring affect corruption? Career concerns and home bias in football refereeing. Applied Economics Letters 20(8), 728-731.

Rottenberg, S. (1956). The baseball players' labor market. Journal of Political Economy 64(3), 242-258.

Rovetta, A. and A. Abate (2021). The Impact of Cheering on Sports Performance: Comparison of Serie A Statistics Before and During COVID-19. Cureus 13(8).

Sacheti, A., I. Gregory-Smith, and D. Paton (2015). Home bias in officiating: evidence from international cricket. Journal of the Royal Statistical Society: Series A (Statistics in Society) 178(3), 741-755.

Sánchez, A. J. and J. M. Lavín (2021). Home advantage in European soccer without crowd. Soccer \& Society 22(1-2), 152-165.

Santana, H. A., O. B. Bettega, and R. A. Dellagrana (2021). An analysis of Bundesliga matches before and after social distancing by COVID-19. Science and Medicine in Football.

Schreyer, D., S. L. Schmidt, and B. Torgler (2018a). Game Outcome Uncertainty and Television Audience Demand: New Evidence from German Football. German Economic Review 19(2), 140-161.

Schreyer, D., S. L. Schmidt, and B. Torgler (2018b). Game Outcome Uncertainty in the English Premier League: Do German Fans Care? Journal of Sports Economics 19(5), 625-644.

Schwartz, B. and S. Barsky (1977). The home advantage. Social Forces 55(3), 641-661.

Scoppa, V. (2008). Are subjective evaluations biased by social factors or connections? An econometric analysis of soccer referee decisions. Empirical Economics 35(1), 123-140.

Scoppa, V. (2021). Social pressure in the stadiums: Do agents change behavior without crowd support? Journal of Economic Psychology 82, 102344.

Sors, F., M. Grassi, T. Agostini, and M. Murgia (2020). The sound of silence in association football: Home advantage and referee bias decrease in matches played without spectators. European Journal of Sport Science. https://doi.org/10.1080/17461391.2020.1845814.

Subak, E. and K. Kaya (2021). Home advantage and audience effect analysis of turkish super league in covid-19 season. Research \& Investigations in Sports Medicine 7.

Sutter, M. and M. Kocher (2004, August). Favoritism of agents - The case of referees' home bias. Journal of Economic Psychology 25(4), 461-469.

Szabó, D. (2021). The impact of social pressure of differing audience size on referees and team performances from a North American perspective. Corvinus economics working papers (cewp), Corvinus University of Budapest.

Tilp, M. and S. Thaller (2020). Covid-19 Has Turned Home Advantage Into Home Disadvantage in the German Soccer Bundesliga. Frontiers in Sports and Active Living 2, 165. 
Wilkinson, T. and R. Pollard (2006). A Temporary Decline in Home Advantage When Moving to a New Stadium. Journal of Sport Behavior 29(2), 190-197.

Wolfson, S., D. Wakelin, and M. Lewis (2005). Football supporters' perceptions of their role in the home advantage. Journal of Sports Sciences 23(4), 365-374.

Wooldridge, J. M. (2010). Econometric Analysis of Cross Section and Panel Data. MIT press.

Wunderlich, F., M. Weigelt, R. Rein, and D. Memmert (2021). How does spectator presence affect football? Home advantage remains in European top-class football matches played without spectators during the COVID-19 pandemic. Plos One 16(3), e0248590. 


\title{
ELIMINATING SUPPORTIVE CROWDS REDUCES REFEREE BIAS
}

\author{
Online Appendix
}

\section{Appendix A RAW DIFFERENCES BETWEen FOOTBALL WITH AND WITHOUT FANS BEFORE COVID-19}

We compare the sample means of final outcomes in matches played with fans and without, across all 33,796 matches in the analysis sample since the beginning of the 2002/03 season and the Covid-19 induced shutdown of professional football in March 2020. The top panel of Table A1 presents these statistics for all matches pooled together, whereas in the three panels below that we focus on the UEFA, Italy and Elite sub-samples, as described in Section III and Tables B1 \& B2. Of the 160 closed doors matches, $35.6 \%$ were won by the team playing at home, 10.2 percentage points less than in matches with fans ( $p$-value $<0.01)$. Mirroring this, the away team was 7.8 percentage points more likely to have won in the sample of closed doors matches than when fans were present $(p$-value $<0.05$ ). These patterns are replicated in the three smaller sub-samples, though the differences between the two types of matches was only statistically significant in the UEFA competitions, where closed doors matches were on average 20.4 percentage points less likely to end in a home win than with fans ( $p$-value $<0.05)$. The lower mean goal difference between teams of 0.30 when matches were played behind closed doors $(p$-value $<0.05)$ also implies less home advantage. There was no significant difference between with and without fans in the mean total goals scored in a match, suggesting that the presence of fans was not related to more attacking play, only reduced home advantage.

In Table A2 and the middle part of Figure A1, we compare the sample means of the different punishments that referees can hand out, between matches with fans and without. Column (I) shows that when spectators were present, referees awarded around 0.4 more yellow cards to players on the away team than on the home team. This was consistent across all the competitions studied here. Likewise, the proportions of matches where the away team was awarded at least one red card or where they gave away at least one penalty were higher than for the home team. These differences are why previous studies have suggested that referee bias toward the home team may account for at least some of the home advantage in football (e.g., Dohmen, 2008b; Dohmen and Sauermann, 2016), though it has proven impossible to completely rule out that the nature of play by teams could also explain these differences in punishments. We find that on average there was no statistically significant difference between matches with fans and without in the mean number of yellow cards awarded to home team players. Likewise, playing behind closed doors was not associated with any significant differences in how likely a given match was to feature a red card or a penalty for either the home or away teams. But on average, 0.4 fewer cards per match were awarded to the away team in empty stadiums ( $p$-value $<0.001$ ), effectively cancelling out the mean difference in yellow cards between teams when fans were present. This pattern is replicated in the three sub-samples, though not significantly so in the UEFA competitions.

Looking beyond the mean, in Figure A2, we plot the sample distribution of the numbers of yellow cards awarded to the home and away teams, comparing matches with and without fans. The distribution for home yellows is similar in both cases, with $30 \%$ of matches having the modal number of two cards. But the modal number of away yellows was reduced to one from two when matches were played behind closed doors. More matches in empty stadiums had zero away yellows than when fans were present, and less had two, three, four and five yellows. In other words, there is a clear shift in the distribution of yellow cards awarded to away teams behind closed doors.

For a smaller sample of matches, we have information on the amount of injury time allowed by referees. ${ }^{1}$ Table A3 and Figure A3, we compare the sample means for these decisions with and without fans. ${ }^{2}$ Injury time in football is at the discretion of the referee, and should reflect how disrupted the play was by stoppages during a half. One rule that referees are supposed to apply is the addition of thirty seconds for each player

\footnotetext{
${ }^{1}$ Note, this is for the actual amount of minutes played after 45 minutes in each half, as opposed to the amount of injury time signalled to the players and crowd by the officials shortly before the end of normal time during matches.

${ }^{2}$ The total (closed doors) numbers of matches in the sample for which injury time details were available from espn.co.uk/football are: All, 13,331 (77); UEFA, 3,427 (31); Elite, 9904 (46).
} 
substitution, which mostly take place in the second half. In column (I) of Table A3, we show that on average, with fans in the stadium, over two minutes more injury time was awarded at the end of the second half compared with the first half.

Several studies have pointed toward injury time as a way in which referee bias relates to home advantage in football (e.g., Sutter and Kocher, 2004; Garicano et al., 2005; Dohmen, 2008b; Scoppa, 2008). Specifically, if a referee is affected by social pressure form the home crowd, then we might expect him/her to award more injury time when the home team is losing at the end of 90 minutes, allowing a greater chance for them to catch up, and vice versa if the home team is winning. We would also expect these effects to disappear if the absolute goal difference between the home and away team at the end of regular time is large enough that the final result is effectively already decided, normally two goals or more, because then there will be less pressure from the home crowd, many of whom may already be on their way to the car park.

In Table A3, we show the average amount of injury time awarded in the second half of matches depending on the goal difference at 90 minutes. More time was generally awarded when a match was close, and more so when the away team was leading by a single goal. This was the case in both the UEFA and Elite competitions, and is consistent with what the previous literature has found about the effects of social pressure on referee bias. In columns (II) \& (III) of Online Appendix Table A3, we show that the amount of injury time awarded in both the first and second half was on average significantly less, by 0.3-0.4 minutes ( $p$-value $<0.05$ ), in the pooled sample of closed doors matches. But there is no evidence that this decrease was associated with whatever the match scoreline was at 90 minutes. Because of the small sample size, in what follows we don't carry out any regression analysis of injury time and how it depended on match situations. But this could be an area of interest for future research as the number of closed doors matches has increased following the Covid-19 outbreak. Not least, one way to definitively test whether referee bias exists in the awarding of injury time, affected by the presence of fans, would be to look at the impact from the number of substitutions, since these should each result in an additional 30 seconds regardless of which team made them.

The results above could suggest that the presence or not of fans in stadiums affects home advantage in football through the decision making of the referee. But it is possible that changes in the nature of match play also have a role and, for example, could account for the reduced number of yellow cards awarded to away team players. To explore this further, we look at several metrics of player and team performances within matches. In Table A4 and the final seven statistics in Figure A1, we compare the sample means of these metrics between matches with and without fans. ${ }^{3}$ The average amount of ball possession in closed doors matches was $50.0 \%$, an insignificant reduction of 1.1 percentage points compared with when fans were allowed into stadiums. Whether a penalty kick leads directly to a goal is an outcome which ought to be almost entirely independent of the referee, apart from the rare cases where the referee deems a kick must be retaken for some infringement. In matches behind closed doors, fewer (more) penalty kicks were missed (saved) by away team players and more (fewer) were missed (saved) by home team players. Though these difference were not statistically significant, owing to the small sample sizes, they are consistent with home support motivating and improving home team player performances but distracting and worsening away team player performances. These events could be looked at more closely in future research, not least because past studies have found evidence of athletes choking under the pressure of home support and the size of the crowd (e.g., Dohmen, 2008a, in football; Böheim et al., 2019, in basketball; Harb-Wu and Krumer, 2019, in biathlon; Jane, 2021 in baseball).

In Table A4, we also show that the percentages of shots on target, i.e., shots that would have led to a goal without being blocked, were greater in closed doors matches than with fans, though not significantly so. But the percentage of shots on target which were saved was significantly higher in closed doors matches, by 10 and 12 percentage points $(p$-value $<0.05$ ) for home and away team goalkeepers, respectively. This pattern was prevalent in both the UEFA and Elite competitions. One potential explanation would be that goalkeepers were less distracted by crowd noise without fans and their performances improved. Another explanation would be that shots were easier to save behind closed doors, perhaps because the ball contrasted more with

\footnotetext{
${ }^{3}$ The information on penalty kicks is available for all sample matches, but the other metrics are only available for the same smaller samples in which fouls were studied.
} 
the background of empty seats or players were shooting further away from the goal, although the percentage of shots on target was not significantly different without fans.

TABLE A1: Comparison of sample means for final outcomes between matches with fans and without, 2002-2020

\begin{tabular}{|c|c|c|c|}
\hline & $\begin{array}{l}\text { With fans } \\
\text { (I) }\end{array}$ & $\begin{array}{l}\text { Closed doors } \\
\text { (II) }\end{array}$ & $\begin{array}{l}\text { Diff. } \\
\text { (III) }\end{array}$ \\
\hline \multicolumn{4}{|l|}{ All } \\
\hline Home win $(\%)$ & 45.8 & 35.6 & $10.2^{* *}$ \\
\hline Draw $(\%)$ & 28.2 & 30.6 & -2.4 \\
\hline Away win (\%) & 25.9 & 33.8 & $-7.8^{*}$ \\
\hline Home goals & 1.45 & 1.23 & $0.22^{*}$ \\
\hline Away goals & 1.05 & 1.14 & -0.09 \\
\hline Goal diff. & 0.40 & 0.09 & $0.30^{*}$ \\
\hline Total goals & 2.50 & 2.37 & 0.13 \\
\hline \multicolumn{4}{|c|}{ European Competition (UEFA) } \\
\hline Home win $(\%)$ & 49.3 & 28.9 & $20.4^{*}$ \\
\hline Draw $(\%)$ & 23.9 & 28.9 & -5.1 \\
\hline Away win $(\%)$ & 26.8 & 42.1 & $-15.3^{*}$ \\
\hline Home goals & 1.61 & 1,39 & 0.22 \\
\hline Away goals & 1.10 & 1.37 & -0.27 \\
\hline Goal diff. & 0.51 & 0.03 & 0.48 \\
\hline Total goals & 2.71 & 2.76 & -0.05 \\
\hline \multicolumn{4}{|l|}{ Italy } \\
\hline Home win $(\%)$ & 45.0 & 36.9 & 8.1 \\
\hline Draw $(\%)$ & 29.3 & 33.0 & -3.7 \\
\hline Away win $(\%)$ & 25.7 & 30.1 & -4.4 \\
\hline Home goals & 1.42 & 1.21 & 0.21 \\
\hline Away goals & 1.05 & 1.09 & -0.03 \\
\hline Goal diff. & 0.37 & 0.13 & 0.24 \\
\hline Total goals & 2.47 & 2.30 & 0.17 \\
\hline \multicolumn{4}{|c|}{ Serie A \& Ligue 1 (Elite) } \\
\hline Home win $(\%)$ & 45.7 & 39.6 & 6.1 \\
\hline Draw $(\%)$ & 27.8 & 28.3 & -0.5 \\
\hline Away win (\%) & 26.5 & 32.1 & -5.5 \\
\hline Home goals & 1.45 & 1.21 & 0.25 \\
\hline Away goals & 1.06 & 1.15 & -0.08 \\
\hline Goal diff. & 0.39 & 0.06 & 0.33 \\
\hline Total goals & 2.52 & 2.36 & 0.16 \\
\hline
\end{tabular}

Notes.- $* * *, * *, *$ indicate significant differences in means between matches with fans and without at $0.1 \%, 1 \%$ and $5 \%$ levels, respectively, two-sided $t$-tests. See Table B1 for $N$ s. Source.- author calculations using worldfootball.net; accessed 14 March 2020. 
TABLE A2: Comparison of sample means for punishments between matches with fans and without, 2002-2020

\begin{tabular}{|c|c|c|c|}
\hline & $\begin{array}{l}\text { With fans } \\
\text { (I) }\end{array}$ & $\begin{array}{l}\text { Closed doors } \\
\text { (II) }\end{array}$ & $\begin{array}{l}\text { Diff. } \\
\text { (III) }\end{array}$ \\
\hline \multicolumn{4}{|l|}{$\overline{A l l}$} \\
\hline Home yellow cards & 1.93 & 1.93 & 0.01 \\
\hline Away yellow cards & 2.28 & 1.90 & $0.38^{* * *}$ \\
\hline Home red cards $>0$ & 0.11 & 0.14 & -0.03 \\
\hline Away red cards $>0$ & 0.15 & 0.12 & 0.04 \\
\hline Home penalties against $>0$ & 0.07 & 0.07 & 0.00 \\
\hline Away penalties against $>0$ & 0.11 & 0.14 & -0.03 \\
\hline \multicolumn{4}{|c|}{ European Competition (UEFA) } \\
\hline Home yellow cards & 1.70 & 1.50 & 0.20 \\
\hline Away yellow cards & 2.13 & 1.89 & 0.24 \\
\hline Home red cards $>0$ & 0.08 & 0.08 & 0.00 \\
\hline Away red cards $>0$ & 0.11 & 0.11 & 0.01 \\
\hline Home penalties against $>0$ & 0.06 & 0.08 & -0.02 \\
\hline Away penalties against $>0$ & 0.10 & 0.16 & -0.05 \\
\hline \multicolumn{4}{|l|}{ Italy } \\
\hline Home yellow cards & 2.10 & 2.16 & -0.05 \\
\hline Away yellow cards & 2.40 & 2.00 & $0.40^{* *}$ \\
\hline Home red cards $>0$ & 0.13 & 0.17 & -0.05 \\
\hline Away red cards $>0$ & 0.17 & 0.12 & 0.04 \\
\hline Home penalties against $>0$ & 0.08 & 0.07 & 0.01 \\
\hline Away penalties against $>0$ & 0.11 & 0.15 & -0.04 \\
\hline \multicolumn{4}{|l|}{ Serie A \& Ligue 1 (Elite) } \\
\hline Home yellow cards & 1.86 & 1.91 & -0.47 \\
\hline Away yellow cards & 2.21 & 1.57 & $0.64^{* * *}$ \\
\hline Home red cards $>0$ & 0.10 & 0.15 & -0.05 \\
\hline Away red cards $>0$ & 0.10 & 0.15 & -0.00 \\
\hline Home penalties against $>0$ & 0.07 & 0.06 & 0.02 \\
\hline Away penalties against $>0$ & 0.11 & 0.13 & -0.02 \\
\hline
\end{tabular}

Notes.- $* * * * * *$ indicate significant differences in means between matches with fans and without at $0.1 \%, 1 \%$ and $5 \%$ levels, respectively, two-sided $t$-tests. See Table B1 for Ns. Source.- author calculations using worldfootball.net; accessed 14 March 2020. 
TABLE A3: Comparison of sample means of injury time (mins) between matches with fans and without, 2002-2020

\begin{tabular}{|c|c|c|c|}
\hline & $\begin{array}{l}\text { With fans } \\
\text { (I) }\end{array}$ & $\begin{array}{l}\text { Closed doors } \\
\text { (II) }\end{array}$ & $\begin{array}{l}\text { Diff. } \\
\text { (III) }\end{array}$ \\
\hline \multicolumn{4}{|l|}{ All } \\
\hline 1 st half & 1.93 & 1.58 & $0.34^{*}$ \\
\hline 2nd half & 4.10 & 3.69 & $0.41^{*}$ \\
\hline 2nd half: away $>1$ up at 90 mins & 3.68 & 2.83 & 0.85 \\
\hline 2nd half: away 1 up at 90 mins & 4.44 & 4.00 & 0.44 \\
\hline 2nd half: even at 90 mins & 4.28 & 3.60 & 0.68 \\
\hline 2nd half: home 1 up at 90 mins & 4.26 & 3.82 & 0.44 \\
\hline 2nd half: home $>1$ up at $90 \mathrm{mins}$ & 3.53 & 4.10 & -0.57 \\
\hline \multicolumn{4}{|l|}{ European Competition (UEFA) } \\
\hline 1st half & 1.47 & 1.23 & 0.24 \\
\hline 2nd half & 3.11 & 2.55 & 0.57 \\
\hline 2nd half: away $>1$ up at 90 mins & 3.08 & 1.6 & 1.48 \\
\hline 2nd half: away 1 up at 90 mins & 3.34 & 3.10 & 0.24 \\
\hline 2nd half: even at 90 mins & 3.12 & 2.60 & 0.52 \\
\hline 2nd half: home 1 at 90 mins & 3.15 & 2.20 & 0.95 \\
\hline 2nd half: home $>1$ up at $90 \mathrm{mins}$ & 2.93 & 3.00 & -0.07 \\
\hline \multicolumn{4}{|l|}{ Serie A \& Ligue 1 (Elite) } \\
\hline 1 st half & 2.09 & 1.83 & 0.26 \\
\hline 2nd half & 4.43 & 4.46 & -0.02 \\
\hline 2nd half: away $>1$ up at 90 mins & 3.92 & 3.71 & 0.21 \\
\hline 2nd half: away 1 up at 90 mins & 4.83 & 5.13 & -0.30 \\
\hline 2nd half: even at 90 mins & 4.64 & 4.60 & 0.04 \\
\hline 2nd half: home 1 at 90 mins & 4.64 & 4.50 & 0.14 \\
\hline 2nd half: home $>1$ up at $90 \mathrm{mins}$ & 3.76 & 4.22 & -0.46 \\
\hline
\end{tabular}

Notes.- $* * *, * * *$ indicate significant differences in means between matches with fans and without at $0.1 \%, 1 \%$ and $5 \%$ levels, respectively, two-sided $t$-tests. See Table B1 for Ns. Source.- author calculations using worldfootball.net and espn.co.uk/football; accessed 14 March 2020. 
TABLE A4: Comparison of player performance sample means between matches with fans and without, 2002/03-2019/20

\begin{tabular}{lccc}
\hline & $\begin{array}{c}\text { With fans } \\
\text { (I) }\end{array}$ & $\begin{array}{c}\text { Closed doors } \\
\text { (II) }\end{array}$ & $\begin{array}{c}\text { Diff. } \\
\text { (III) }\end{array}$ \\
\hline All & & & \\
Home possession (\%) & 51.1 & 50.0 & 1.1 \\
Home penalties missed (\%) & 21.2 & 27.3 & -6.1 \\
Away penalties missed (\%) & 20.4 & 9.1 & 11.4 \\
Home shots on target (SOT) (\%) & 35.0 & 36.0 & -1.0 \\
Away shots on target (SOT) (\%) & 34.3 & 37.2 & -2.9 \\
Home SOT saved (\%) & 73.8 & 83.7 & $-9.9^{*}$ \\
Away SOT saved (\%) & 72.4 & 84.9 & $-12.5^{* *}$ \\
European Competition (UEFA) & & & 3.0 \\
Home possession (\%) & 51.4 & 48.4 & -4.1 \\
Home shots on target (SOT) (\%) & 37.5 & 41.6 & $-8.4^{*}$ \\
Away shots on target (SOT) (\%) & 37.1 & 45.5 & -11.2 \\
Home SOT saved (\%) & 85.6 & 91.4 & \\
Away SOT saved (\%) & 85.8 & 97.1 & -0.5 \\
Serie A \& Ligue 1 (Elite) & & & 3.4 \\
Home possession (\%) & 51.0 & 51.5 & 3.9 \\
Home shots on target (SOT) (\%) & 34.1 & 30.7 & -6.4 \\
Away shots on target (SOT) (\%) & 33.3 & 29.4 & -5.7 \\
Home SOT saved (\%) & 69.7 & 76.1 & 73.4 \\
Away SOT saved (\%) & 67.7 & & \\
\hline
\end{tabular}

Notes.- $* * *, * * *$ indicate significant differences in means between matches with fans and without at $0.1 \%, 1 \%$ and $5 \%$ levels, respectively, two-sided $t$-tests. See Table B1 for Ns. Source.- author calculations using worldfootball.net and espn.co.uk/football; accessed 14 March 2020. 
FIGURE A1: Differences in sample means of football match outcomes: closed doors vs with fans, 2002-2020

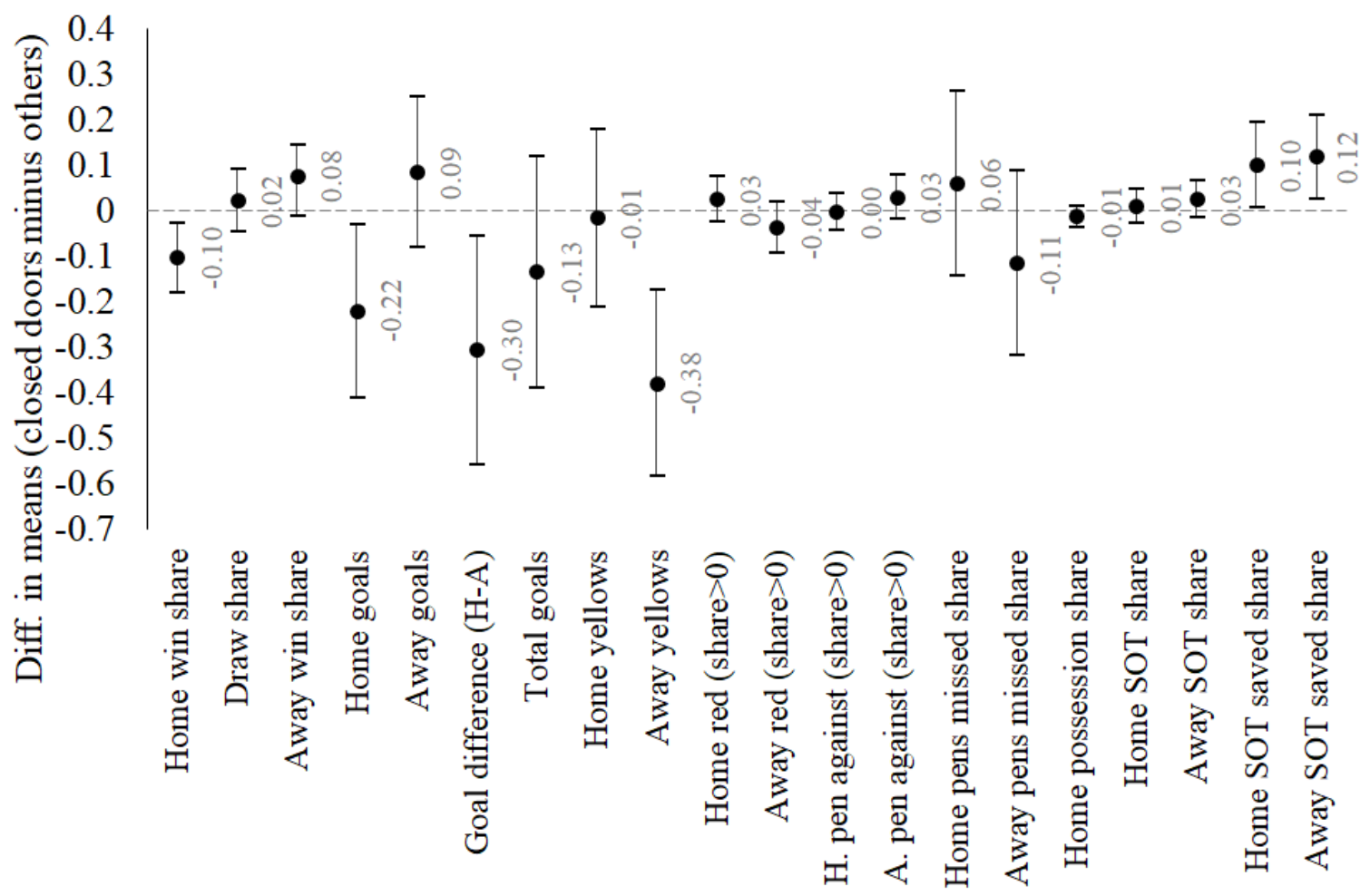

Notes.- Uses all matches in the UEFA Champions League, Europa League, Italian Serie A, Serie B, Serie C, Coppa Italia and French Ligue 1 since the beginning of the 2002/03 season to April 2020. See Figure 2 and Tables B1-B2 for further sample description. See Table A1, A2 and A4 for the underlying mean values with and without fans. $95 \%$ confidence intervals displayed. Source.- author calculations using worldfootball.net and espn.co.uk/football; accessed 14 March 2020. 
FIGURE A2: Sample distribution of yellow cards awarded over matches: with fans vs without, 2020

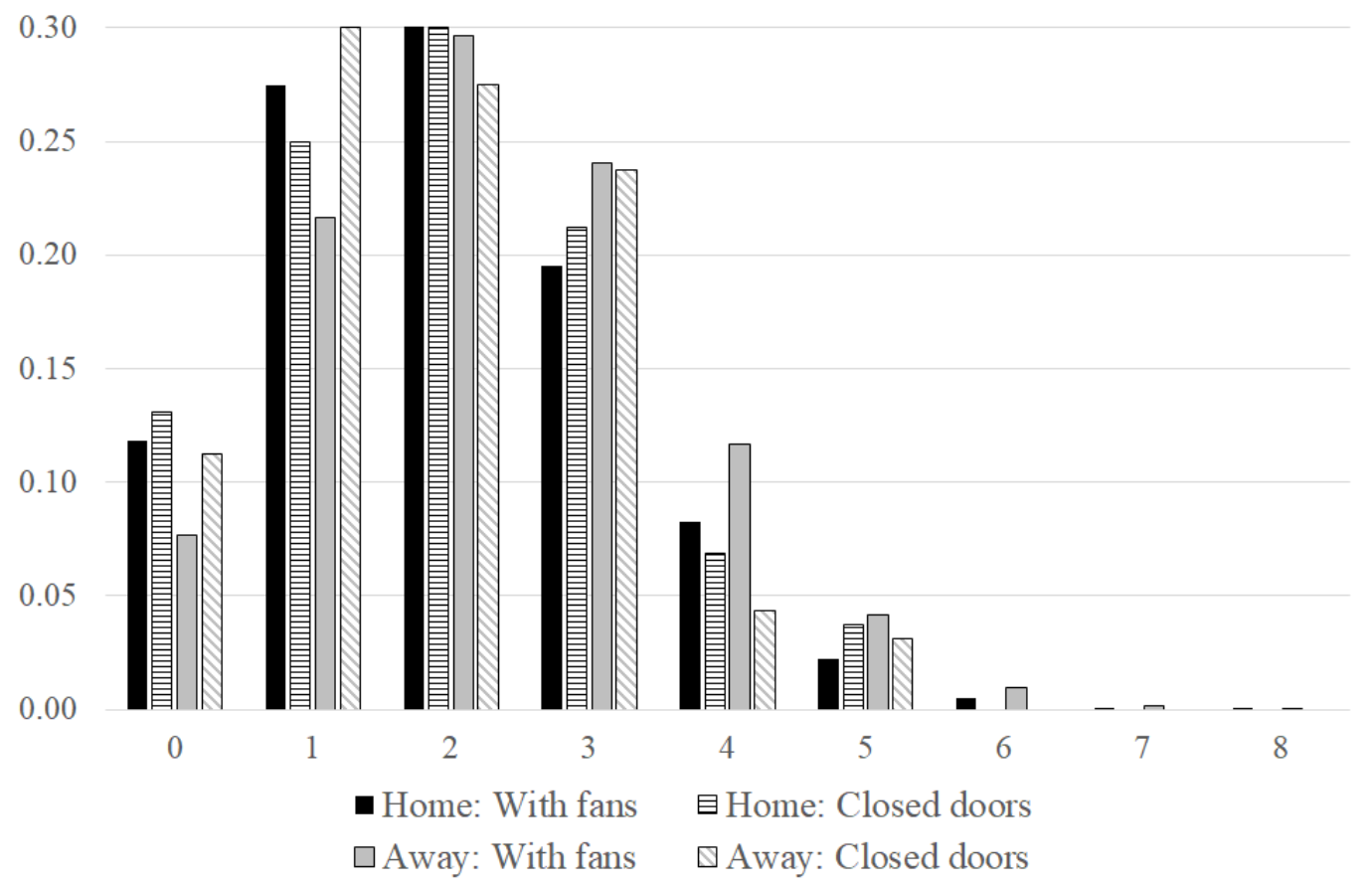

Notes.- All sample matches. Source.- worldfootball.net; accessed 14 March 2020.

FIGURE A3: Differences in sample means of injury time awarded, depending on the match situation at 90 mins: closed doors vs with fans, 2002-2020

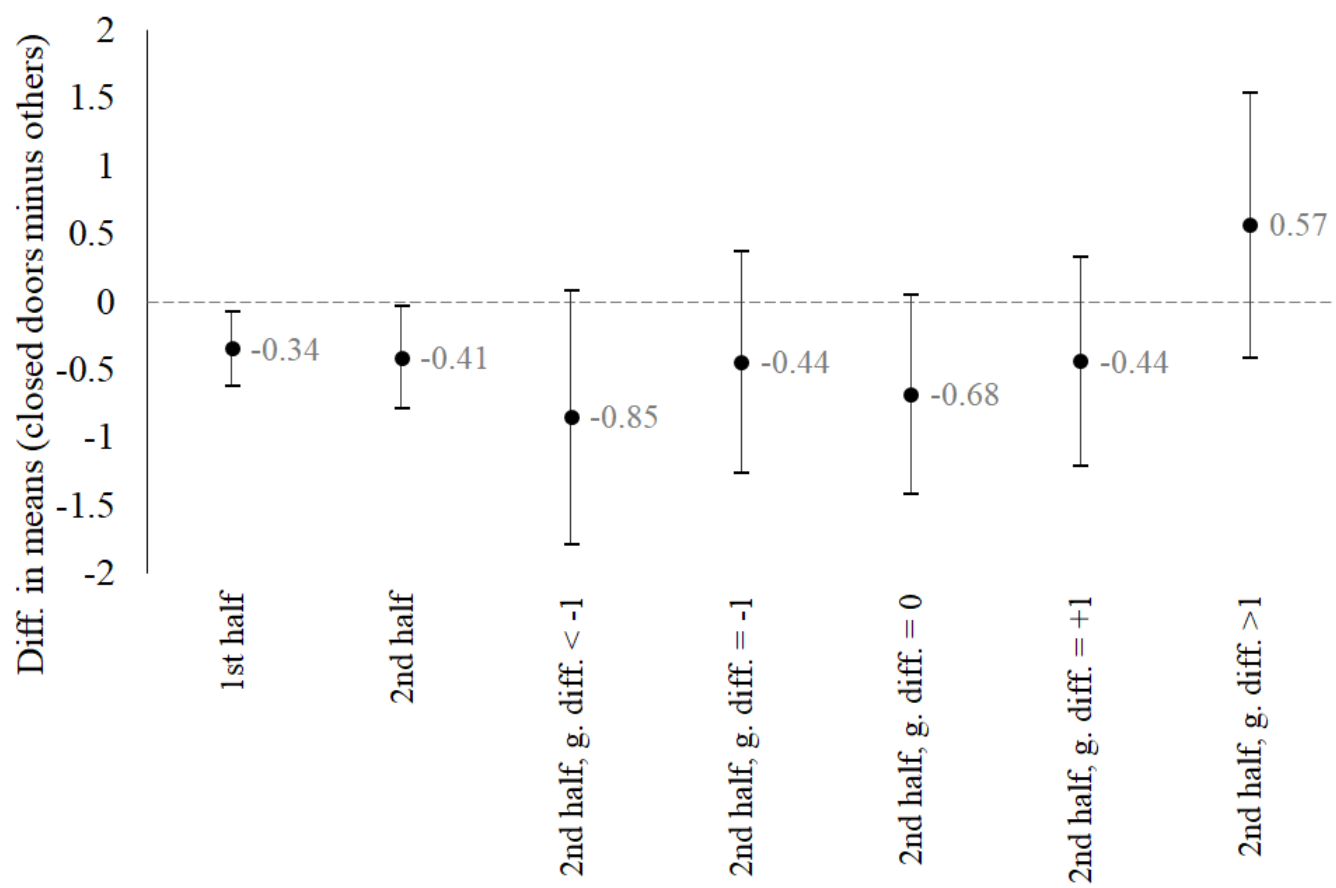

Notes.- "2nd half g. diff $=-1$ " refers to matches where at 90 minutes the away team was leading by one goal, etc. Uses all matches in the UEFA Champions League, Europa League, Italian Serie A, and French Ligue 1 since the beginning of the 2002/03 season to April 2020. See Figure 2 and Tables B1-B2 for further sample description. See Table A3 for the underlying mean values with and without fans. $95 \%$ confidence intervals displayed. Source.- author calculations using worldfootball.net and espn.co.uk/football; accessed 14 March 2020. 


\section{Appendix B ADDITIONAL TABLES}

TABLE B1: Summary statistics over football matches (Part I), 2002-2020: By Competition

\begin{tabular}{|c|c|c|c|c|c|}
\hline & Mean & St. Dev. & Min. & Median & Max. \\
\hline \multicolumn{6}{|l|}{ All } \\
\hline Attendance (1000s) & 16.0 & 15.9 & 0.0 & 11.1 & 98.8 \\
\hline Home Elo rating & 1085 & 107 & 732 & 1076 & 1532 \\
\hline Away Elo rating & 1079 & 107 & 741 & 1069 & 1517 \\
\hline$N$ of home teams & & & 458 & & \\
\hline$N$ of away teams & & & 581 & & \\
\hline$N$ of home-away team pairs & & & 13,993 & & \\
\hline$N$ of referees & & & 701 & & \\
\hline$N$ of matches & & & 33,796 & & \\
\hline$N$ behind closed doors & & & 160 & & \\
\hline \multicolumn{6}{|c|}{ European Competition (UEFA) } \\
\hline Attendance $(1000 \mathrm{~s})$ & 29.8 & 19.5 & 0.0 & 25.5 & 98.8 \\
\hline Home Elo rating & 1095 & 100 & 835 & 1090 & 1524 \\
\hline Away Elo rating & 1096 & 101 & 836 & 1089 & 1510 \\
\hline$N$ of home teams & & & 284 & & \\
\hline$N$ of away teams & & & 375 & & \\
\hline$N$ of home-away team pairs & & & 4,767 & & \\
\hline$N$ of referees & & & 392 & & \\
\hline$N$ of matches & & & 5,684 & & \\
\hline$N$ behind closed doors & & & 38 & & \\
\hline \multicolumn{6}{|l|}{ Italy } \\
\hline Attendance (1000s) & 10.8 & 12.8 & 0.0 & 6.0 & 81.8 \\
\hline Home Elo rating & 1074 & 111 & 732 & 1064 & 1532 \\
\hline Away Elo rating & 1066 & 111 & 740 & 1055 & 1517 \\
\hline$N$ of home teams & & & 171 & & \\
\hline$N$ of away teams & & & 204 & & \\
\hline$N$ of home-away team pairs & & & 7,962 & & \\
\hline$N$ of referees & & & 296 & & \\
\hline$N$ of matches & & & 21,377 & & \\
\hline$N$ behind closed doors & & & 103 & & \\
\hline \multicolumn{6}{|l|}{ Serie A \& Ligue 1 (Elite) } \\
\hline Attendance (1000s) & 22.3 & 13.7 & 0.0 & 18.2 & 81.8 \\
\hline Home Elo rating & 1135 & 107 & 824 & 1122 & 1532 \\
\hline Away Elo rating & 1130 & 106 & 860 & 1114 & 1517 \\
\hline$N$ of home teams & & & 85 & & \\
\hline$N$ of away teams & & & 85 & & \\
\hline$N$ of home-away team pairs & & & 2,650 & & \\
\hline$N$ of referees & & & 191 & & \\
\hline$N$ of matches & & & 13,301 & & \\
\hline$N$ behind closed doors & & & 53 & & \\
\hline
\end{tabular}

Notes.- statistics are calculated over all matches in the analysis sample since the beginning of the 2002/03 season to April 2020. Excludes matches where the home team appeared only once in a competition in a given season. Source.worldfootball.net; accessed 14 March 2020. 
TABLE B2: Summary statistics over football matches (Part II), 2002-2020

\begin{tabular}{|c|c|c|c|c|c|}
\hline & Mean & St. Dev. & Min. & Median & Max. \\
\hline \multicolumn{6}{|l|}{ All } \\
\hline Home win $(\%)$ & 45.8 & & & & \\
\hline Draw $(\%)$ & 28.2 & & & & \\
\hline Away win (\%) & 26.0 & & & & \\
\hline Goal diff. (Home-Away) & 0.40 & 1.62 & -9 & 0 & 15 \\
\hline Yellow cards & 4.21 & 1.98 & 0 & 4 & 13 \\
\hline Red cards & 0.29 & 0.57 & 0 & 0 & 5 \\
\hline Penalty kicks & 0.19 & 0.45 & 0 & 0 & 5 \\
\hline Penalties missed (\%) & 21 & 40 & 0 & 0 & 100 \\
\hline \multicolumn{6}{|c|}{ European Competition (UEFA) } \\
\hline Home win $(\%)$ & 49.2 & & & & \\
\hline Draw $(\%)$ & 23.9 & & & & \\
\hline Away win (\%) & 26.9 & & & & \\
\hline Goal diff. (Home-Away) & 0.51 & 1.85 & -7 & 0 & 8 \\
\hline Yellow cards & 3.83 & 2.07 & 0 & 4 & 12 \\
\hline Red cards & 0.20 & 0.47 & 0 & 0 & 3 \\
\hline Penalty kicks & 0.18 & 0.45 & 0 & 0 & 5 \\
\hline Penalties missed (\%) & 31 & 45 & 0 & 0 & 100 \\
\hline \multicolumn{6}{|l|}{ Italy } \\
\hline Home win $(\%)$ & 44.9 & & & & \\
\hline Draw $(\%)$ & 29.3 & & & & \\
\hline Away win $(\%)$ & 25.8 & & & & \\
\hline Goal diff. (Home-Away) & 0.37 & 1.54 & -7 & 0 & 15 \\
\hline Yellow cards & 4.50 & 1.94 & 0 & 4 & 13 \\
\hline Red cards & 0.33 & 0.60 & 0 & 0 & 5 \\
\hline Penalty kicks & 0.20 & 0.46 & 0 & 0 & 5 \\
\hline Penalties missed & 18 & 37 & 0 & 0 & 100 \\
\hline \multicolumn{6}{|l|}{ Serie A \& Ligue 1 (Elite) } \\
\hline Home win $(\%)$ & 45.7 & & & & \\
\hline Draw $(\%)$ & 27.8 & & & & \\
\hline Away win (\%) & 26.6 & & & & \\
\hline Goal diff. (Home-Away) & 0.39 & 1.63 & -9 & 0 & 9 \\
\hline Yellow cards & 4.07 & 1.95 & 0 & 4 & 11 \\
\hline Red cards & 0.27 & 0.55 & 0 & 0 & 5 \\
\hline Penalty kicks & 0.19 & 0.45 & 0 & 0 & 5 \\
\hline Penalties missed & 24 & 42 & 0 & 0 & 100 \\
\hline
\end{tabular}

Notes.- see also Table B1. Source.- worldfootball.net; accessed 14 March 2020. 


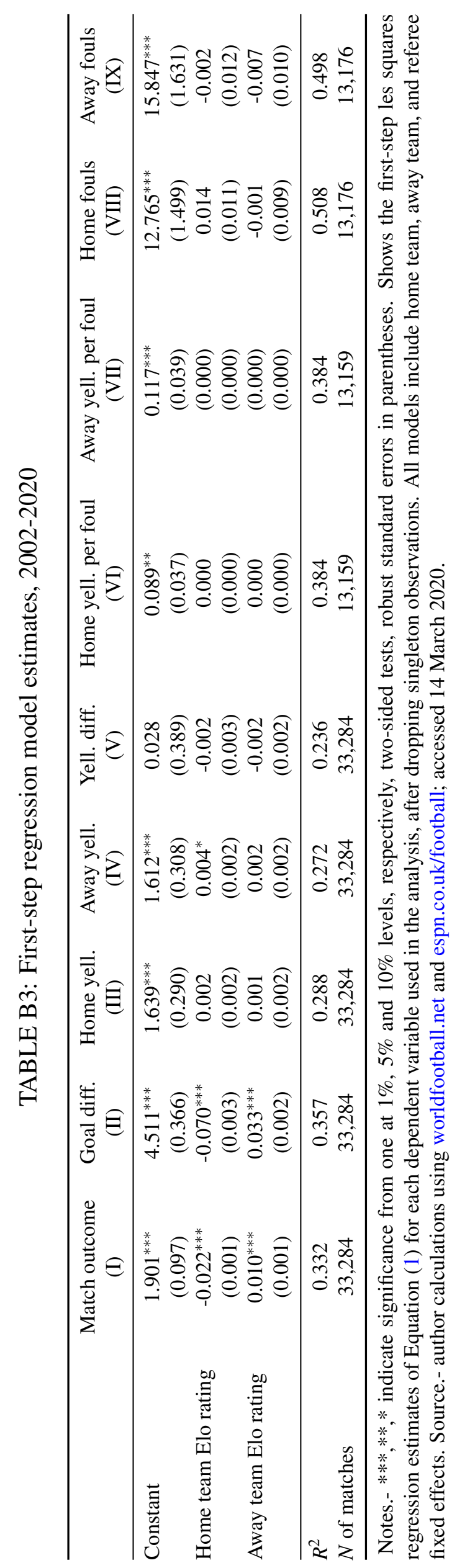


TABLE B4: Regression model estimates for the effect of playing behind closed doors on MATCH OUTCOMES, 2002-2020

\begin{tabular}{lcccc}
\hline & $(\mathrm{I})$ & $(\mathrm{II})$ & $(\mathrm{III})$ & $(\mathrm{IV})$ \\
\hline Constant $(\widehat{\alpha})$ & $0.574^{* * *}$ & 0.040 & 0.027 & \\
& $(0.032)$ & $(0.050)$ & $(0.075)$ & \\
Closed doors $(\widehat{\lambda})$ & -0.048 & -0.025 & -0.025 & -0.056 \\
& $(0.044)$ & $(0.039)$ & $(0.040)$ & $(0.037)$ \\
First-step predicted outcome $(\widehat{\beta})$ & & $0.913^{* * *}$ & $0.936^{* * *}$ & \\
& & $(0.078)$ & $(0.132)$ & \\
\hline Matchup fixed effects & No & No & Yes & No \\
$R^{2}$ & 0.003 & 0.217 & 0.563 & 0.323 \\
$N$ of matches & 280 & 280 & 280 & 33,248 \\
$N$ of matchups/closed doors matches & 97 & 97 & 97 & 160 \\
\hline
\end{tabular}

Notes.- $* * * * * * *$ indicate significance from zero at 1\%,5\% and $10 \%$ levels, respectively, two-sided tests, standard errors in parentheses are robust to matchup clusters. Columns (I)-(III) show linear regression estimates of Equation (2), where the dependent variable is the match result, taking the value 1 if the home team won, 0.5 if it ended in a draw and 0 if the away team won, i.e., coefficients should be interpreted as marginal effects on the probability of the home team winning, or three times the effect on the achieved points gap between teams. Column (IV) shows linear regression estimates of Equation (1) for the whole sample of matches for seasons 2002/03-19/20 described in Table B1, dropping singletons, with an added dummy variable for closed doors matches, as well as Elo rating controls, home-team-season, away-team-season and referee fixed effects. Source.- author calculations using worldfootball.net and espn.co.uk/football; accessed 14 March 2020.

TABLE B5: Regression model estimates for the effect of playing matches behind closed doors on goal differences (home minus away), 2002-2020: MORE RESTRICTED MATCHING

\begin{tabular}{lcccc}
\hline & $(\mathrm{I})$ & $(\mathrm{II})$ & $(\mathrm{III})$ & $(\mathrm{IV})$ \\
\hline Constant $(\widehat{\alpha})$ & $0.430^{* * *}$ & 0.039 & -0.016 & \\
& $(0.156)$ & $(0.143)$ & $(0.052)$ & \\
Closed doors $(\widehat{\lambda})$ & -0.241 & -0.122 & -0.105 & -0.146 \\
& $(0.206)$ & $(0.174)$ & $(0.169)$ & $(0.137)$ \\
First-step predicted outcome $(\widehat{\beta})$ & & $0.880^{* * *}$ & $1.002^{* * *}$ & \\
& & $(0.123)$ & $(0.227)$ & \\
\hline Matchup fixed effects & No & No & Yes & No \\
$R^{2}$ & 0.008 & 0.256 & 0.693 & 0.357 \\
$N$ of matches & 158 & 158 & 158 & 33,284 \\
$N$ of matchups/closed doors matches & 79 & 79 & 79 & 160 \\
\hline
\end{tabular}

Notes.- $* * * * * * *$ indicate significance from zero at $1 \%, 5 \%$ and $10 \%$ levels, respectively, two-sided tests, standard errors in parentheses are robust to matchup clusters in all models. Columns (I)-(III) show linear regression estimates of Equation (2), where the dependent variable is the difference between the numbers of goals scored by the home and away teams (home minus away). These are comparable to Table 4 in the main text, but here use a more restricted matching process between closed doors and non-closed doors matches. Column (IV) shows linear regression estimates of Equation (1) for the whole sample of matches for seasons 2002/03-19/20 described in Table 2, after dropping singletons, with an added dummy variable for closed doors matches, as well as Elo rating controls, home-team-season, away-team-season and referee fixed effects (i.e., repeating column (IV) of Table 4). Source.- author calculations using worldfootball.net and espn.co.uk/football; accessed 14 March 2020. 
TABLE B6: Regression model estimates for the effect of playing matches behind closed doors on yellow card differences (home minus away), 2002-2020: MORE RESTRICTED MATCHING

\begin{tabular}{lcccc}
\hline & $(\mathrm{I})$ & $(\mathrm{II})$ & $(\mathrm{III})$ & (IV) \\
\hline Constant $(\widehat{\alpha})$ & $-0.405^{* *}$ & -0.023 & 0.089 & \\
& $(0.181)$ & $(0.170)$ & $(0.147)$ & \\
Closed doors $(\widehat{\lambda})$ & $0.531^{* *}$ & 0.294 & 0.232 & 0.224 \\
& $(0.266)$ & $(0.238)$ & $(0.236)$ & $(0.138)$ \\
First-step predicted outcome $(\widehat{\beta})$ & & $1.063^{* * *}$ & $1.376^{* * *}$ & \\
& & $(0.181)$ & $(0.248)$ & \\
\hline Matchup fixed effects & No & No & Yes & No \\
$R^{2}$ & 0.028 & 0.255 & 0.608 & 0.236 \\
$N$ of matches & 158 & 158 & 158 & 33,248 \\
$N$ of matchups/closed doors matches & 79 & 79 & 79 & 160 \\
\hline
\end{tabular}

Notes.- $* * * * * * *$ indicate significance from zero at $1 \%, 5 \%$ and $10 \%$ levels, respectively, two-sided tests, standard errors in parentheses are robust to matchup clusters. Columns (I)-(III) show linear regression estimates of Equation (2), where the dependent variable is the difference between the numbers of yellow cards awarded to the home and away teams (home minus away). These are comparable to Table 5 in the main text, but here use a more restricted matching process between closed doors and non-closed doors matches. Column (IV) shows linear regression estimates of Equation (1) for the whole sample of matches for seasons 2002/03-19/20 described in Table 2, dropping singletons, with an added dummy variable for closed doors matches, as well as Elo rating controls, home-team-season, away-team-season and referee fixed effects (i.e., repeating column (IV) of Table 5). Source.- author calculations using worldfootball.net and espn.co.uk/football; accessed 14 March 2020.

TABLE B7: Poisson regression estimates (incident rate ratio) for the effect of playing matches behind closed doors on home and away yellow cards, 2002-2020: MORE RESTRICTED MATCHING

\begin{tabular}{|c|c|c|c|c|c|c|}
\hline & \multicolumn{3}{|c|}{ Home cards } & \multicolumn{3}{|c|}{ Away cards } \\
\hline & (I) & (II) & (III) & (IV) & (V) & (VI) \\
\hline Constant $(\widehat{\alpha})$ & $\begin{array}{c}1.987^{* * *} \\
(0.139)\end{array}$ & $\begin{array}{c}0.695^{* *} \\
(0.114)\end{array}$ & $\begin{array}{c}0.650 \\
(0.182)\end{array}$ & $\begin{array}{c}2.392^{* * *} \\
(0.130)\end{array}$ & $\begin{array}{c}0.913 \\
(0.163)\end{array}$ & $\begin{array}{c}0.926 \\
(0.247)\end{array}$ \\
\hline Closed doors $(\widehat{\lambda})$ & $\begin{array}{c}1.023 \\
(0.097)\end{array}$ & $\begin{array}{c}0.921 \\
(0.078)\end{array}$ & $\begin{array}{c}0.899 \\
(0.078)\end{array}$ & $\begin{array}{c}0.788^{* * *} \\
(0.069)\end{array}$ & $\begin{array}{c}0.795^{* * *} \\
(0.063)\end{array}$ & $\begin{array}{c}0.794^{* * *} \\
(0.063)\end{array}$ \\
\hline First-step predicted outcome $(\widehat{\beta})$ & & $\begin{array}{c}1.654^{* * *} \\
(0.109)\end{array}$ & $\begin{array}{c}1.770^{* * *} \\
(0.216)\end{array}$ & & $\begin{array}{c}1.491^{* * *} \\
(0.100)\end{array}$ & $\begin{array}{c}1.523^{* * *} \\
(0.160)\end{array}$ \\
\hline Matchup fixed effects & No & No & Yes & No & No & Yes \\
\hline Log pseudol'hood & -256.5 & -239.3 & -215.2 & -252.7 & -242.9 & -220.7 \\
\hline Pearson $\chi^{2}$ test, $p$-value & 0.990 & 0.997 & & 0.995 & 1.000 & \\
\hline Log l'hood ratio test, $p$-value & 0.705 & 1.000 & & 1.000 & 1.000 & \\
\hline$N$ of matches & 158 & 158 & 156 & 158 & 158 & 158 \\
\hline$N$ of matchups/closed doors matches & 79 & 79 & 77 & 79 & 79 & 79 \\
\hline
\end{tabular}

Notes.- $* * * * * * *$ indicate significance from one at $1 \%, 5 \%$ and $10 \%$ levels, respectively, two-sided tests, standard errors in parentheses are robust to matchup clusters. Columns (I)-(VI) display Poisson regression equivalent estimates of Equation (2), where the dependent variables are the numbers of yellow cards awarded to the home and away teams. These are comparable to Table 6 in the main text, but here use a more restricted matching process between closed doors and non-closed doors matches. Source.- author calculations using worldfootball.net and espn.co.uk/football; accessed 14 March 2020. 
TABLE B8: Regression model estimates for the effect of playing matches behind closed doors on GOAL DIFFERENCES (home minus away), 2002-2020: sub-samples

\begin{tabular}{lcccc}
\hline & $\begin{array}{c}\text { All } \\
(\mathrm{I})\end{array}$ & $\begin{array}{c}\text { Calciopoli } \\
(\mathrm{II})\end{array}$ & $\begin{array}{c}\text { Italy } \\
(\text { III })\end{array}$ & $\begin{array}{c}2019 / 20 \\
(\mathrm{IV})\end{array}$ \\
\hline Constant $(\widehat{\alpha})$ & -0.030 & -0.155 & -0.059 & -0.123 \\
& $(0.052)$ & $(0.100)$ & $(0.062)$ & $(0.127)$ \\
Closed doors $(\widehat{\lambda})$ & -0.131 & $-0.472^{* *}$ & -0.072 & 0.044 \\
& $(0.139)$ & $(0.221)$ & $(0.163)$ & $(0.274)$ \\
First-step predicted outcome $(\widehat{\beta})$ & $0.932^{* * *}$ & $0.508^{*}$ & $0.820^{* * *}$ & $0.807^{* * *}$ \\
& $(0.128)$ & $(0.258)$ & $(0.160)$ & $(0.245)$ \\
\hline Matchup fixed effects & Yes & Yes & Yes & Yes \\
$R^{2}$ & 0.581 & 0.609 & 0.562 & 0.631 \\
$N$ of matches & 280 & 98 & 211 & 68 \\
$N$ of matchups/closed doors matches & 97 & 31 & 73 & 29 \\
\hline
\end{tabular}

Notes.- $* * *, * * *$ indicate significance from zero at $1 \%, 5 \%$ and $10 \%$ levels, respectively, two-sided tests, standard errors in parentheses are robust to matchup clusters in all models. Column (I) repeats the main estimates from Column(III) of Table 4. Column (II) uses only closed doors matches in Italy during the Calciopoli scandal (i.e., the 2006/07 season, as per Pettersson-Lidbom and Priks, 2010) in the estimation of Equation (2). Column (II) uses only matches in Italian domestic football. Column (IV) uses only closed doors matches in the 2019/20 season. Source.- author calculations using worldfootball.net and espn.co.uk/football; accessed 14 March 2020.

TABLE B9: Poisson regression model estimates (incident rate ratio) for the effect of playing matches behind closed doors on HOME yellow cards, 2002-2020: sub-samples

\begin{tabular}{lcccc}
\hline & $\begin{array}{c}\text { All } \\
(\mathrm{I})\end{array}$ & $\begin{array}{c}\text { Calciopoli } \\
(\mathrm{II})\end{array}$ & $\begin{array}{c}\text { Italy } \\
(\text { III })\end{array}$ & $\begin{array}{c}2019 / 20 \\
(\mathrm{IV})\end{array}$ \\
\hline Constant $(\widehat{\alpha})$ & $0.582^{* *}$ & 0.297 & 0.584 & 0.907 \\
& $(0.098)$ & $(0.083)$ & $(0.117)$ & $(0.314)$ \\
Closed doors $(\widehat{\lambda})$ & 0.903 & 0.969 & 0.897 & 0.964 \\
& $(0.060)$ & $(0.121)$ & $(0.068)$ & $(0.766)$ \\
First-step predicted outcome $(\widehat{\beta})$ & $1.780^{* * *}$ & $2.217^{* * *}$ & $1.794^{* * *}$ & $1.556^{* * *}$ \\
& $(0.122)$ & $(0.234)$ & $(0.144)$ & $(0.229)$ \\
\hline Matchup fixed effects & Yes & Yes & Yes & Yes \\
$N$ of matches & 278 & 98 & 211 & 66 \\
$N$ of matchups/closed doors matches & 96 & 31 & 73 & 29 \\
\hline
\end{tabular}

Notes.- $* * *, * * *$ indicate significance from one at $1 \%, 5 \%$ and $10 \%$ levels, respectively, two-sided tests, standard errors in parentheses are robust to matchup clusters in all models. Column (I) repeats the main estimates from Column(III) of Table 6. Column (II) uses only closed doors matches in Italy during the Calciopoli scandal (i.e., the 2006/07 season, as per Pettersson-Lidbom and Priks, 2010) in the estimation of Equation (2). Column (II) uses only matches in Italian domestic football. Column (IV) uses only closed doors matches in the 2019/20 season. Source.- author calculations using worldfootball.net and espn.co.uk/football; accessed 14 March 2020. 
TABLE B10: Poisson regression model estimates (incident rate ratio) for the effect of playing matches behind closed doors on AWAY yellow cards, 2002-2020: sub-samples

\begin{tabular}{lcccc}
\hline & $\begin{array}{c}\text { All } \\
(\mathrm{I})\end{array}$ & $\begin{array}{c}\text { Calciopoli } \\
(\text { II })\end{array}$ & $\begin{array}{c}\text { Italy } \\
(\text { III })\end{array}$ & $\begin{array}{c}2019 / 20 \\
(\text { IV })\end{array}$ \\
\hline Constant $(\widehat{\alpha})$ & 0.975 & 1.367 & 1.145 & $2.052^{* *}$ \\
& $(0.147)$ & $(0.266)$ & $(0.195)$ & $(0.727)$ \\
Closed doors $(\widehat{\lambda})$ & $0.808^{* * *}$ & $0.754^{* * *}$ & $0.806^{* * *}$ & 0.930 \\
First-step predicted outcome $(\widehat{\beta})$ & $(0.057)$ & $(0.079)$ & $(0.067)$ & $(0.151)$ \\
& $1.463^{* * *}$ & $1.287^{* * *}$ & $1.379^{* * *}$ & 1.057 \\
& $(0.088)$ & $(0.092)$ & $(0.092)$ & $(0.168)$ \\
\hline Matchup fixed effects & Yes & Yes & Yes & Yes \\
$N$ of matches & 280 & 98 & 211 & 68 \\
$N$ of matchups/closed doors matches & 97 & 31 & 73 & 29 \\
\hline
\end{tabular}

Notes.- $* * *, * *, *$ indicate significance from one at $1 \%, 5 \%$ and $10 \%$ levels, respectively, two-sided tests, standard errors in parentheses are robust to matchup clusters in all models. Column (I) repeats the main estimates from Column(VI) of Table 6. Column (II) uses only closed doors matches in Italy during the Calciopoli scandal (i.e., the 2006/07 season, as per Pettersson-Lidbom and Priks, 2010) in the estimation of Equation (2). Column (II) uses only matches in Italian domestic football. Column (IV) uses only closed doors matches in the 2019/20 season. Source.- author calculations using worldfootball.net and espn.co.uk/football; accessed 14 March 2020.

TABLE B11: Regression estimates for the effect of playing matches behind closed doors on HOME and AWAY YELLOW CARDS PER FOUL, 2002-2020

\begin{tabular}{|c|c|c|c|c|c|c|}
\hline & \multicolumn{3}{|c|}{ Home yellows per foul } & \multicolumn{3}{|c|}{ Away yellows per foul } \\
\hline & (I) & (II) & (III) & (IV) & $(\mathrm{V})$ & (VI) \\
\hline Constant $(\widehat{\alpha})$ & $\begin{array}{c}0.135^{* * *} \\
(0.010)\end{array}$ & $\begin{array}{c}-0.044^{* * *} \\
(0.012)\end{array}$ & $\begin{array}{c}-0.051^{* *} \\
(0.022)\end{array}$ & $\begin{array}{c}0.155^{* * *} \\
(0.011)\end{array}$ & $\begin{array}{c}0.030 \\
(0.025)\end{array}$ & $\begin{array}{l}-0.017 \\
(0.028)\end{array}$ \\
\hline Closed doors $(\widehat{\lambda})$ & $\begin{array}{c}-0.002 \\
(0.018)\end{array}$ & $\begin{array}{l}-0.008 \\
(0.012)\end{array}$ & $\begin{array}{l}-0.010 \\
(0.012)\end{array}$ & $\begin{array}{c}-0.045^{* * *} \\
(0.016)\end{array}$ & $\begin{array}{c}-0.047^{* * *} \\
(0.014)\end{array}$ & $\begin{array}{r}-0.045^{* * *} \\
(0.014)\end{array}$ \\
\hline First-step predicted outcome $(\widehat{\beta})$ & & $\begin{array}{c}1.189^{* * *} \\
(0.085)\end{array}$ & $\begin{array}{c}1.234^{* * *} \\
(0.148)\end{array}$ & & $\begin{array}{c}0.0825^{* * *} \\
(0.152)\end{array}$ & $\begin{array}{c}1.127^{* * *} \\
(0.181)\end{array}$ \\
\hline Matchup fixed effects & No & No & Yes & No & No & Yes \\
\hline$R^{2}$ & 0.000 & 0.544 & 0.689 & 0.065 & 0.255 & 0.654 \\
\hline$N$ of matches & 101 & 101 & 101 & 101 & 101 & 101 \\
\hline$N$ of matchups/closed doors matches & 35 & 35 & 35 & 35 & 35 & 35 \\
\hline
\end{tabular}

Notes.- $* * *, * *, *$ indicate significance from one at $1 \%, 5 \%$ and $10 \%$ levels, respectively, two-sided tests, standard errors in parentheses are robust to matchup clusters. Columns (I)-(VI) display estimates of Equation (2), where the dependent variables are the numbers of fouls awarded against the home and away teams per foul committed. Source.- author calculations using worldfootball.net and espn.co.uk/football; accessed 14 March 2020. 
TABLE B12: Poisson regression estimates (incident rate ratio) for the effect of playing matches behind closed doors on HOME and AWAY FOULS, 2002-2020

\begin{tabular}{|c|c|c|c|c|c|c|}
\hline & \multicolumn{3}{|c|}{ Home fouls } & \multicolumn{3}{|c|}{ Away fouls } \\
\hline & (I) & (II) & (III) & (IV) & (V) & (VI) \\
\hline Constant $(\widehat{\alpha})$ & $\begin{array}{c}14.92^{* * *} \\
(0.635)\end{array}$ & $\begin{array}{c}5.582^{* * *} \\
(0.816)\end{array}$ & $\begin{array}{c}7.061^{* * *} \\
(1.505)\end{array}$ & $\begin{array}{c}15.33^{* * *} \\
(0.532)\end{array}$ & $\begin{array}{c}6.664^{* * *} \\
(0.987)\end{array}$ & $\begin{array}{c}7.198^{* * *} \\
(1.396)\end{array}$ \\
\hline Closed doors $(\widehat{\lambda})$ & $\begin{array}{c}.974 \\
(0.056)\end{array}$ & $\begin{array}{c}0.923^{*} \\
(0.044)\end{array}$ & $\begin{array}{c}0.931 \\
(0.052)\end{array}$ & $\begin{array}{c}0.993 \\
(0.060)\end{array}$ & $\begin{array}{c}1.007 \\
(0.054)\end{array}$ & $\begin{array}{c}1.001 \\
(0.054)\end{array}$ \\
\hline First-step predicted outcome $(\widehat{\beta})$ & & $\begin{array}{c}1.069^{* * *} \\
(0.011)\end{array}$ & $\begin{array}{c}1.054^{* * *} \\
(0.015)\end{array}$ & & $\begin{array}{c}1.056^{* * *} \\
(0.010)\end{array}$ & $\begin{array}{c}1.052^{* * *} \\
(0.013)\end{array}$ \\
\hline Matchup fixed effects & No & No & Yes & No & No & Yes \\
\hline Log pseudol'hood & -303.2 & -272.4 & -254.9 & -293.3 & -277.2 & -257.4 \\
\hline Pearson $\chi^{2}$ test, $p$-value & 0.000 & 0.705 & & 0.037 & 0.587 & \\
\hline Log l'hood ratio test, $p$-value & 0.000 & 1.000 & & 0.023 & 0.522 & \\
\hline$N$ of matches & 101 & 101 & 101 & 101 & 101 & 101 \\
\hline$N$ of matchups/closed doors matches & 35 & 35 & 35 & 35 & 35 & 35 \\
\hline
\end{tabular}

Notes.- $* * *, * * *$ indicate significance from one at $1 \%, 5 \%$ and $10 \%$ levels, respectively, two-sided tests, standard errors in parentheses are robust to matchup clusters. Columns (I)-(VI) display Poisson regression equivalent estimates of Equation (2), incident rate ratios, where the dependent variables are the numbers of fouls awarded against the home and away teams. Source.- author calculations using worldfootball.net and espn.co.uk/football; accessed 14 March 2020. 